\title{
THE MANTLE CAVITY OF SOME OF THE ERYCINIDAE, MONTACUTIDAE AND GALEOM- MATIDAE WITH SPECIAL REFERENCE TO THE CILIARY MECHANISMS
}

\author{
By Mary Leyborne Popham, Ph.D. \\ Department of Zoology, University of Bristol
}

(Text-figs. I-26)

\begin{tabular}{|c|c|c|c|c|c|c|c|c|}
\hline \multicolumn{9}{|c|}{ CONTENTS } \\
\hline Introduction & & . & . & & & & & 549 \\
\hline Material . & . & . & . & & & & & 550 \\
\hline Kellia suborbic & lar & (Mor & tagu & . & ${ }^{\circ}$ & & & $55 \mathrm{I}$ \\
\hline Lasaea rubra & Mor & agu) & & & & & & 556 \\
\hline Montacuta fer & ugin & $s a(\mathrm{M}$ & onta & & & & & 560 \\
\hline Montacuta sub & tria & (Mo & ntag & & & & & 564 \\
\hline Mysella bident & ta & Ionta & gu) & & & & & 568 \\
\hline Devonia perrie & $i(\Lambda$ & lard) & . & & & & & 572 \\
\hline Galeomma turt & oni & owerb & & & & & & 576 \\
\hline Discussion & . & . & . & . & & & • & 582 \\
\hline Summary & . & . & . & . & & & • & 585 \\
\hline References & . & . & . & . & & & & 586 \\
\hline
\end{tabular}

INTRODUCTION

Despite various accounts of the occurrence, habits and general anatomy of several species of the order Leptonacea, there exists no general account of this group, unique amongst the Lamellibranchia in that it is composed largely of commensal species. In particular, little is known of the structure and mode of functioning of the organs in the mantle cavity, while little attempt has been made to correlate the various peculiarities of structure found in these animals with their specialized mode of life.

Descriptions of the shells of these species were early recorded. All except Devonia were described by Forbes \& Hanley (1853) and Jeffreys (1863), and later accounts have been given of the external appearance and habits of these species. There are many descriptions of Kellia and Lasaea, the most complete being that of Pelseneer (1903) who investigated the general anatomy of Lasaea, and later (I9II) of the whole order (the Lucinacea according to his classification). Pelseneer (I89I) also described the anatomy of Montacuta ferruginosa, and later accounts of Montacuta (Marshall, I89I), and also of Mysella (as Montacuta bidentata) were given by Winckworth (1923, I924), Gardiner (I928) and Salisbury (1932). The external appearance and habits of Devonia 
were recorded by Jeffreys (I863), but erroneously identified as Montacuta donacina (S. V. Wood) and by Malard (1903) and Winckworth (1930), and the general anatomy by Anthony (I916, as Entovalva) and Ohshima (I930, I93I). Galeomma has been described by Mittre (I847) and Fischer (1887), but again the most complete account of the anatomy is given by Pelseneer (I9II). But apart from Ridewood (1903), who has described the structure, and Atkins (1937), who has described the appearance and mode of functioning of the gills, no previous general investigation of the ciliary mechanisms of the mantle cavity of these members of the Leptonacea has been recorded.

Acknowledgements are due to Prof. C. M. Yonge for his supervision of the preparation of this paper, to the Director and members of the staff of the Plymouth Laboratory for their kindness and help during the time spent there in connexion with this work, and also to $\mathrm{Mr} \mathrm{R}$. Winckworth for valuable criticisms.

\section{MATERIAL}

Two members of the family Erycinidae, Kellia suborbicularis (Montagu) and Lasaea rubra (Montagu), and four members of the family Montacutidae, Montacuta ferruginosa (Montagu), M. substriata (Montagu), Mysella bidentata (Montagu) and Devonia perrieri (Malard), were examined alive. All these are included in the family Leptonidae (Marine Biological Association, I93I). Galeomma turtoni Sowerby, of the family Galeommatidae, was also examined. This family is included with the Leptonidae in the order Leptonacea. The general anatomy and ciliary currents of the mantle cavity were studied and special attention paid to the feeding mechanisms.

Several of each species were examined alive and the ciliary currents in the mantle cavity were observed using powdered carmine. Others were fixed in Bouin's fluid, serial sections were cut at about $6-8 \mu$ and the sections stained in Delafield's haematoxylin and eosin for examination of the general anatomy and details of the ciliation.

The ciliary currents in the mantle cavity of Lasaea rubra were difficult to determine owing to the small size of this species. Some were fixed in Bouin's fluid, cleared in clove oil and examined as whole mounts as they were perfectly transparent when treated in this manner.

Montacuta substriata is small and fragile, and was easily damaged during dissection. Mysella bidentata is also small, but partial dissection was possible without much damage, and the chief ciliary currents were determined.

Devonia perrieri is rare, and it is also fragile and easily damaged during dissection. Although a preliminary examination of the mantle cavity was made, the study was not complete.

Lepton squamosum, L. nitidum as well as Epilepton clarkiae are reported from Salcombe (Marine Biological Association, I93I). Many unsuccessful attempts were made to procure them, for they have apparently disappeared from Salcombe during the last few years. 


\section{Kellia suborbicularis (Montagu)}

K. suborbicularis is free-living. At Plymouth it was found in crevices and holes bored by Pholadidia and Saxicava in soft red sandstone dredged from the Revelstoke Grounds. It was also frequently found in the dead shells of boring molluscs, or in crevices with such small openings that it could only be removed by breaking up the rock. The larvae or small adults must have entered these holes and early settled down there. Some small adults were found crawling on the rock and also in the fine red sand and grey mud which had collected in the crevices (Lebour, 1938). Kellia is also fairly common on all rocky shores near Plymouth.

$K$. suborbicularis is the largest member of this group. The average size is from about $8 \times 6.5$ to II $\times$ I0.5 $\mathrm{mm}$. It has a smooth white glossy shell, oval in shape, with faint concentric striations. The embryonic shell is still visible in the adult near the umbo, and the whole shell has a rounded appearance, being very wide from valve to valve across the thickest part. The shell valves can be closed completely and the foot, mantle and siphons withdrawn. There is therefore no permanent gape.

There are three distinct pallial openings; the anterior inhalent opening which is in the form of a definite siphon, the ventral pedal opening, and the posterior exhalent opening which is also in the form of a siphon. With the exception of the inhalent siphon (Fig. $\mathrm{I}, i$ ) the tissues do not extend beyond the shell in life. The opening has lips formed by the free edges of the mantle, and is surrounded by a band of circular muscle. The exhalent opening is at the same level but posterior. The siphon is shorter and the opening much smaller than that of the inhalent opening (Figs. I, 2, e). The pedal opening extends along the whole of the ventral side and allows extensive movement of the foot.

The foot is hatchet-shaped and large (Fig. 2, $f$ ), the ventral surface acting as a creeping sole. It is solid and not very extensile. The anterior portion has a blunt tip; the posterior portion forms a definite heel, although it does not trail behind as the posterior border is vertical. The ventral surface of the foot is flat, with a byssal groove which opens near the anterior end. The byssal gland is situated in the heel portion of the foot, and this region has a denser appearance than the general mass of pedal muscle.

$K$. suborbicularis is not so active as the other members of the group, it usually lives in a confined space, and the foot is probably rarely used for movement in the adults which are often found attached to the rock by several byssus threads. It is, however, capable of active movement, using its foot as a creeping sole.

\section{Mantle cavity and ciliary currents}

There are two complete demibranchs on each side (Atkins, 1937). The inner demibranch is larger, and extends farther anteriorly and ventrally than the outer (Fig. I, i.d). The outer demibranch has a narrow supra-axial extension (Fig. I, s.e) (Atkins, 1937). The axis of the ctenidium runs diagonally from 
immediately below the umbo towards the posterior ventral border of the shell (Fig. 2, c.a).

The adductors are large, the posterior adductor being larger than the anterior and slightly more ventral in position (Figs. I, 2, a.a, p.a).

Gills. The ciliation on the inner demibranchs is normal. Particles are passed down from the axis towards the free edge of the ctenidium and along the food groove at this edge to the labial palps and the mouth (Fig. 3). On the

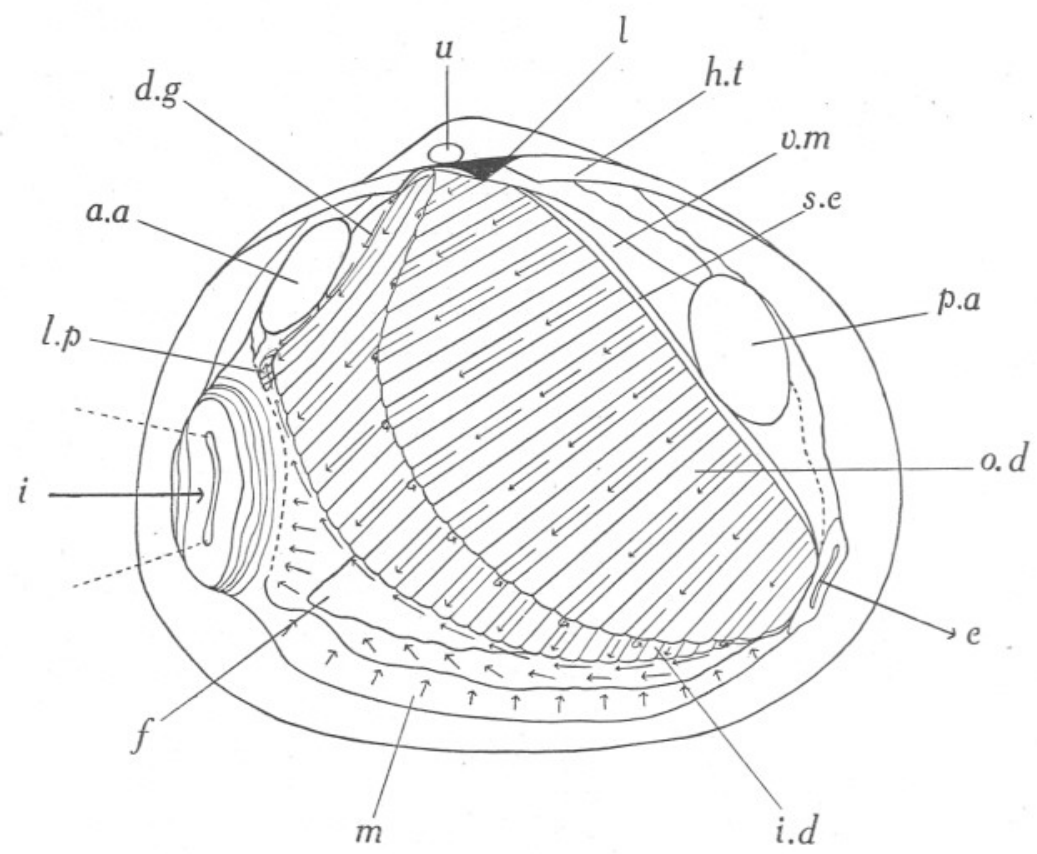

Fig. I. Kellia suborbicularis with the left valve and mantle lobe removed to show the ciliary currents in the mantle cavity. $\times$ Io. a.a, anterior adductor; d.g, distal oral groove; $e$, exhalent current; $f$, foot; h.t, hinge tooth; $i$, inhalent current; $i . d$, inner demibranch; $l$, ligament; l.p, labial palp; $m$, mantle; o.d, outer demibranch; $p . a$, posterior adductor; s.e, supra-axial extension; $u$, umbo; v.m, visceral mass.

outer demibranch, however, the particles pass down the outer, ascending lamella to the free edge, in under this edge and up the inner side of the outer demibranch, i.e. the descending lamella, towards the axis. This is contrary to the normal direction, and has been observed by Atkins (1937). There is no food groove at the distal or free edge (Fig. I). Nevertheless, owing to the presence of a thickening of the filaments at the distal edge of this demibranch, this is regarded as a complete outer demibranch consisting of a descending and an ascending lamella rather than as a single lamella which has been reflected. This is clearly seen in sections. Except for the absence of the groove, the ventral margin is similar in appearance to that of the inner demibranch and is 
strongly ciliated. In the region of the axis some particles are drawn across and passed down the descending lamella of the inner demibranch to the food groove, but there is also a current along the ctenidial axis between the two demibranchs which carries particles towards the mouth. At the anterior end they pass down the anterior border of the inner demibranch in the distal oral groove (Kellogg, I9I5) and so to the labial palps where they are sorted (Fig. 2, l.p). Only very small particles go to the mouth, larger particles are passed off the palps on to the mantle and collect below the inhalent opening. No orally directed currents were observed along the junction of the ascending lamella

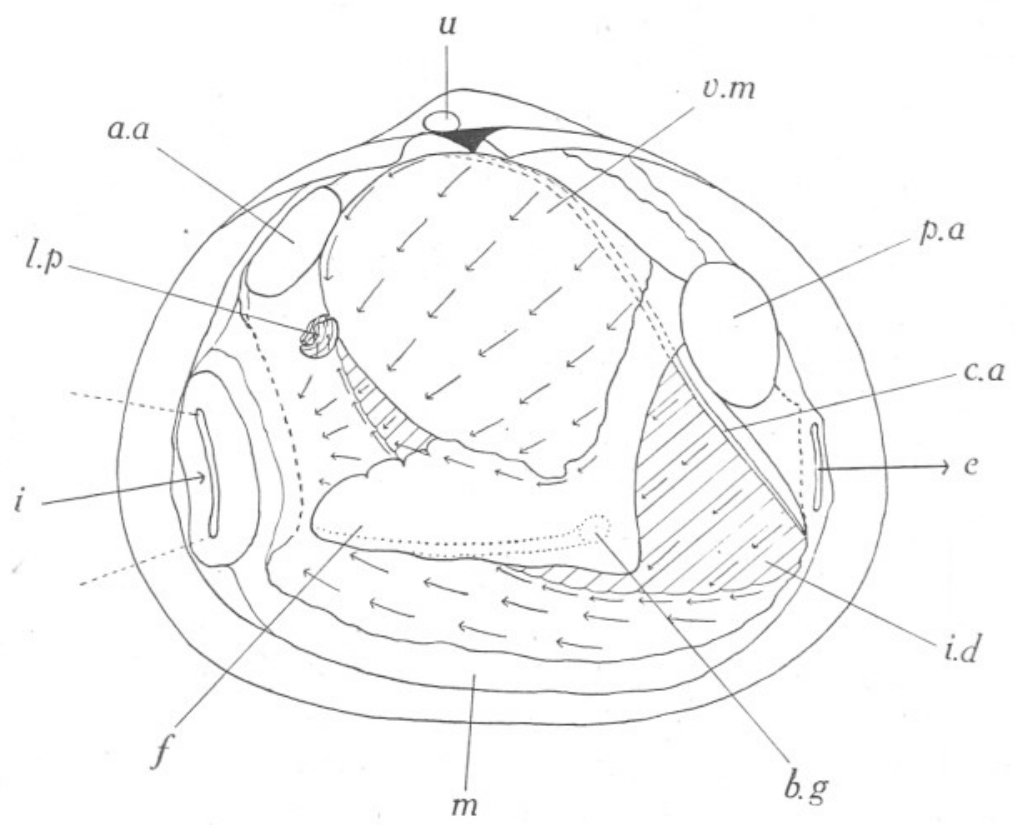

Fig. 2. K. suborbicularis with the left valve, mantle lobe and gill removed to show the ciliary currents on the visceral mass. $\times$ IO. $a . a$, anterior adductor; $b . g$, byssal gland; c.a, axis of ctenidium; $e$, exhalent current; $f$, foot; $i$, inhalent current; i.d, inner demibranch; $l . p$, labial palp; $m$, mantle; $p . a$, posterior adductor; $u$, umbo; v. $m$, visceral mass.

of the inner demibranchs with the visceral mass, or along the junction of the ascending lamella of the outer demibranchs with the mantle. This was also found by Atkins (1937).

Labial palps. There are two pairs of small labial palps (Fig. 3). They are fused anteriorly to form the lips of the mouth $(m o)$, but the free parts are curved away from each other. The opposed surfaces are diagonally ridged. Particles of food and other material are swept on to the palps from the food groove of the inner demibranch which lies between each pair of palps, and from the distal oral groove (Fig. I, d.g). The ciliation of the labial palps is normal (Fig. 3). They act as sorting organs. Large particles and masses of 
waste material entangled in mucus are passed off the palps on to the mantle and are rejected from the mantle cavity. Only the finest particles pass along the proximal oral groove $(p . g)$ at the oral end of the base of the palps into the mouth. Particles pass diagonally across the ridged surface of the palps from the tips to the outer side of the lips of the mouth, and collect in mucusentangled masses (Fig. 3, w) which are removed by the ciliary rejection currents of the mantle. There is also a current up the outer edges and over the smooth outer surfaces of the palps from the base towards the tips, i.e. contrary to the movement over the ridged surface. Particles which do not pass into the

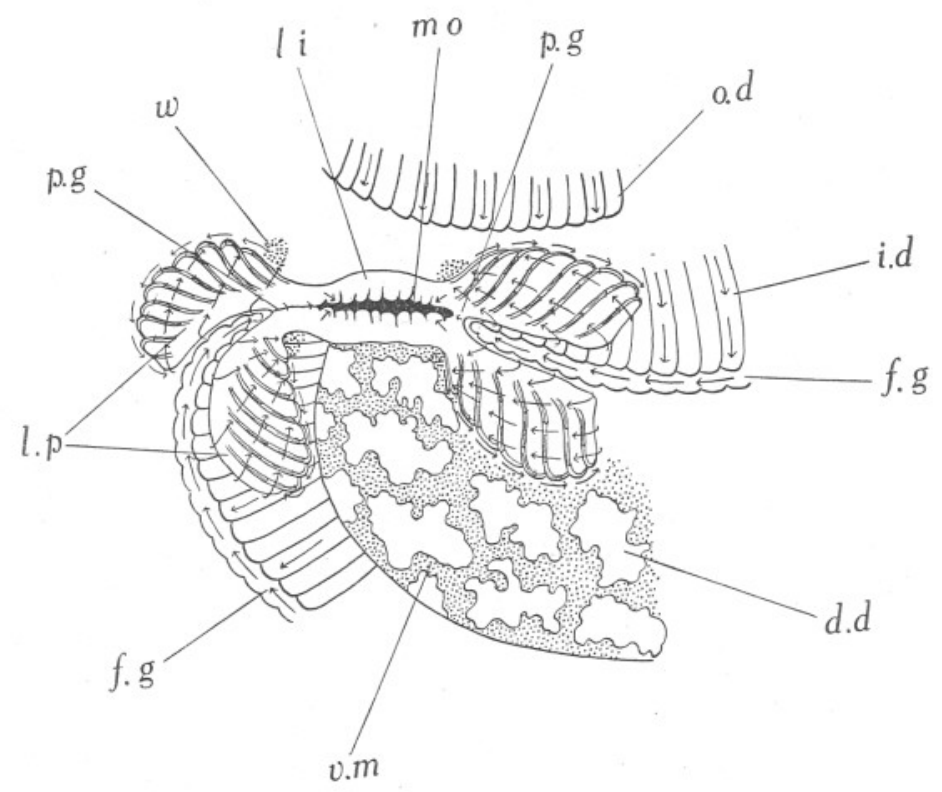

Fig. 3. K. suborbicularis. Ciliary currents on the labial palps. $\times 20 . d . d$, digestive diverticula; f.g, food groove; i.d, inner demibranch; $l i$, lip; l.p, labial palp; mo, mouth; o.d, outer demibranch; $p . g$, proximal oral groove; $v . m$, visceral mass; $w$, waste.

mass of waste material, or which become detached from it, pass up to the tips of the palps in this current and down over the ridged surface where they are sorted further. There is an additional sorting in the grooves of the ridged surface. Moderately fine particles are detached from the main mass, pass up these grooves and into the current passing up the free edge. No current was observed in the middle of each ridge passing in the opposite direction to that in the grooves, as mentioned by Kellogg (I9I5), but that was probably owing to the relatively small size of the palps. The fine particles sorted out from the main mass pass slowly into the mouth along the short proximal oral groove (Fig. 3, p.g).

Visceral mass and foot. The surface of the visceral mass is ciliated and con- 
cerned with the rejection of waste material (Fig. 2). The direction of the currents on the visceral mass is the same as that of the ascending lamella of the inner demibranch which lies over it, from the line of the axis of the ctenidium towards the mouth. Particles of waste material are passed downwards and forwards over the surface of the visceral mass and collect immediately inside the inhalent opening. They also pass forwards along the dorsal region of the foot at its junction with the visceral mass into the main mass of waste material. This appears to be the only ciliated region on the foot.

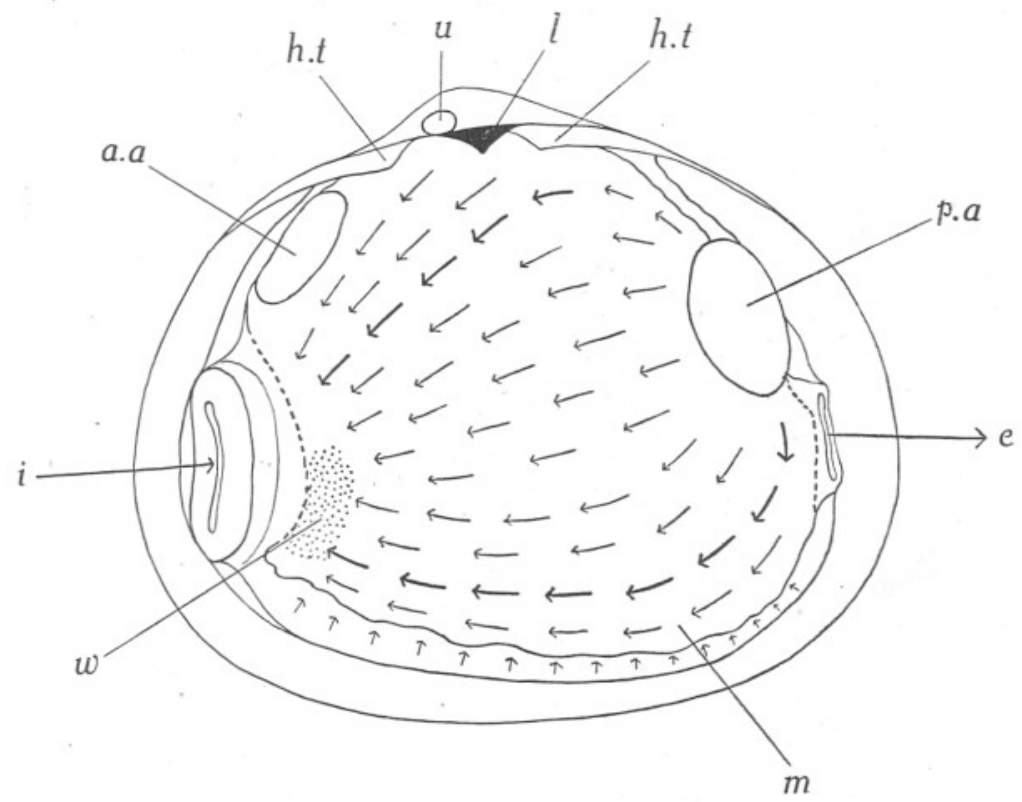

Fig. 4. K. suborbicularis. Ciliary currents on the mantle. $\times$ 10. a.a, anterior adductor; $e$, exhalent current; $h . t$, hinge tooth; $i$, inhalent current; $l$, ligament; $m$, mantle; p.a, posterior adductor; $u$, umbo; $w$, waste.

Mantle. There is an active ciliation of the mantle surface concerned with the rejection of waste material. The general trend is forwards from the posterior adductor towards the inhalent opening (Fig. 4). The cilia are active and the currents are strong over the whole surface, but there are two main currents, one from below the posterior adductor which follows the ventral curve of the shell to the "collecting ground" of waste material inside the inhalent opening, the other passes forwards dorsally but farther from the dorsal border of the shell. The free edges of the mantle around the pedal opening are ciliated. Particles falling on them are passed up into the mantle cavity, they are swept over the mantle edge into the rejection current on the ventral part of the mantle. A large mass of waste material collects inside the inhalent opening entangled in mucus (Fig. 4,w). It is passed out through the inhalent siphon 
by a sudden violent contraction of the adductor muscles, and is shot out against the normal inhalent stream as in other lamellibranchs (Kellogg, I915). Kellia is the only member of this group in which this has been observed.

The exhalent current is normal, water passes out from the suprabranchial cavity through the short exhalent siphon.

The active ciliation of the mantle and the removal of waste through the inhalent opening by muscular contraction prevent silting up of the mantle cavity in this species which usually lives a practically sedentary existence in an environment where there may be a considerable amount of mud.

\section{Lasaea rubra (Montagu)}

L. rubra is found among dead barnacle shells between tide-marks. It occurs in the dead shells or between them, but it has not been observed actually within the shell of living barnacles. It is often attached to the rock or shells by means of a byssus, but is sometimes found crawling on the surface of the rock. The barnacles are so closely packed together that the movements of $L$. rubra must be restricted.

It occurs on all rocky shores in the neighbourhood of Plymouth and is most abundant a few feet below high-water mark. It was collected from Drake's Island and the G.W.R. wharfs at Plymouth, and from the rocks on the shore at Chapel Porth on the North coast of Cornwall.

L. rubra is small, the largest specimens collected measured only $\mathrm{I} \cdot 4 \times \mathrm{I} \cdot 2 \mathrm{~mm}$. and these were fully mature. The shell is a dark reddish brown in colour and is darkest in the region of the umbo. The largest specimens are heavily pigmented, while the shells of the young are practically transparent. The shell is oval, in the young it is only slightly longer than it is broad, but in the large specimens the asymmetry is increased. The umbo is raised above the level of the hinge, and the embryonic shell is still clearly visible in the adult (Fig. 5, $\mathrm{em}$ ). The surface of the shell is smooth with striations following the curve of the shell. The edge is entire. There is no permanent gape between the shell valves.

There are three pallial openings, the anterior inhalent siphon, the ventral pedal opening and the posterior exhalent siphon. The inhalent opening is a definite siphon and extends for a considerable distance beyond the shell valves in life (Fig. 5, $i$ ). When fully expanded it is bell-shaped. The mantle is fused for a short distance below the inhalent siphon and so separates the inhalent from the pedal opening. The large pedal opening extends along the whole of the ventral side. This large opening makes possible the rapid and active pedal movements characteristic of Lasaea. The exhalent opening is the smallest of the pallial openings. The mantle lobes are fused to form a short but distinct siphon which is not visible from the exterior as it never extends beyond the shell valves (Fig. $5, e$ ).

The foot is long and slender with a rounded tip. It is very extensile and when fully extended it may exceed the length of the shell (Fig. 5, $f$ ). The 
anterior end of the foot is cylindrical in shape, the whole foot becoming wider towards the shell and flattened dorso-ventrally. It is capable of active movement and when moving about the foot is first pushed out in an anterior and slightly ventral direction. The anterior tip of the foot appears first and seeks about, the heel or posterior portion of the foot then appears and the whole animal moves forward with a gliding motion using the ventral surface of the foot as a creeping sole. The anterior tip of the foot becomes attached, apparently by a sucker-like action, and the whole animal is pulled forward by a

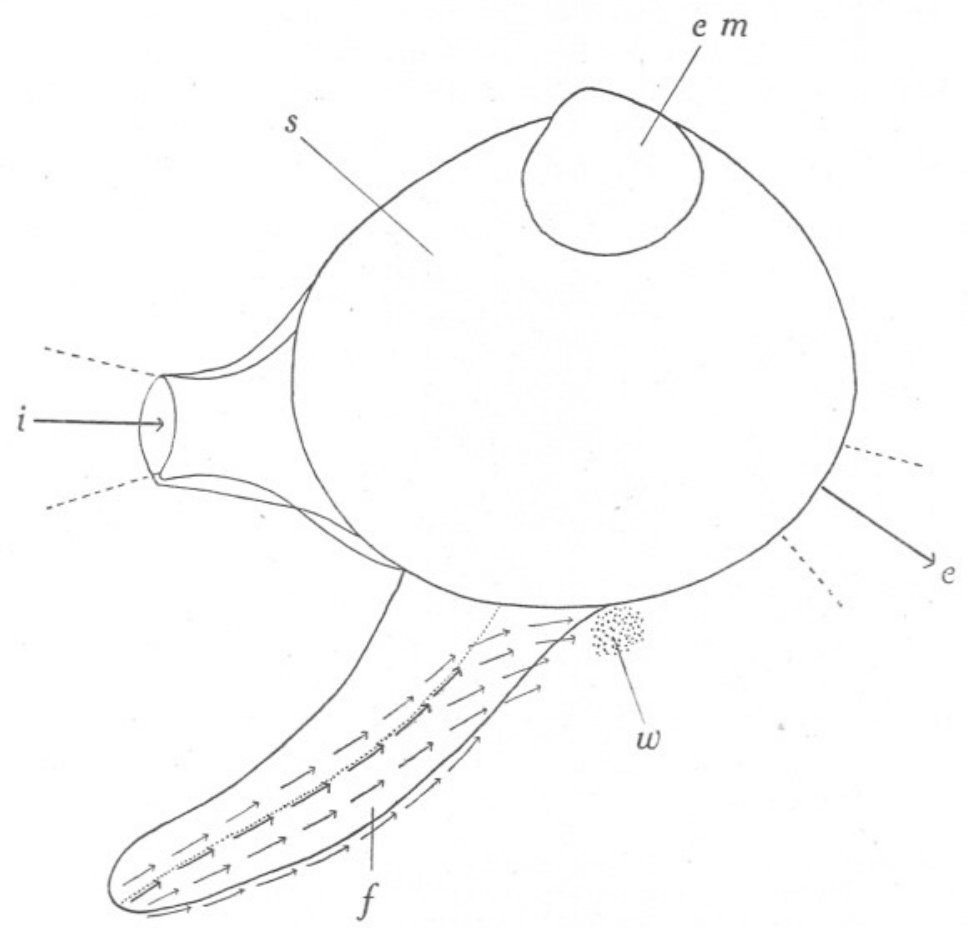

Fig. 5. Lasaea rubra. External appearance. $\times 60 . e$, exhalent current; em, embryonic shell; $f$, foot; $i$, inhalent current; $s$, shell; $w$, waste.

contraction of the pedal muscles and tilted slightly forwards over the foot. During this movement the foot is partially withdrawn between the shell valves. The anterior part is then pushed out again and the animal moves forward by a series of short violent movements. These movements are arhythmic, like those which occur in certain Gastropoda such as Aporrhais (Yonge, 1937). The direction of movement is determined by the tip of the foot which can be turned in all directions.

The byssal gland is situated in the posterior portion of the foot. There is a byssal groove along the ventral surface of the foot which opens out just behind the anterior tip. This groove becomes a closed duct posteriorly. Several strong 
threads are produced, their position being determined by the direction of the anterior tip of the foot, and the angle between the threads usually varies from 30 to $45^{\circ}$. The byssal gland is very active and if several animals are left in a dish they become bound together by a network of byssal threads so that they are difficult to separate.

\section{Mantle cavity and ciliary currents}

Each ctenidium consists of a complete inner demibranch consisting of a descending and a very short ascending lamella, and an outer demibranch consisting of a descending lamella only, the distal edge of which is attached to the adjacent mantle lobe (Fig. 6). When this mantle lobe was removed the outer

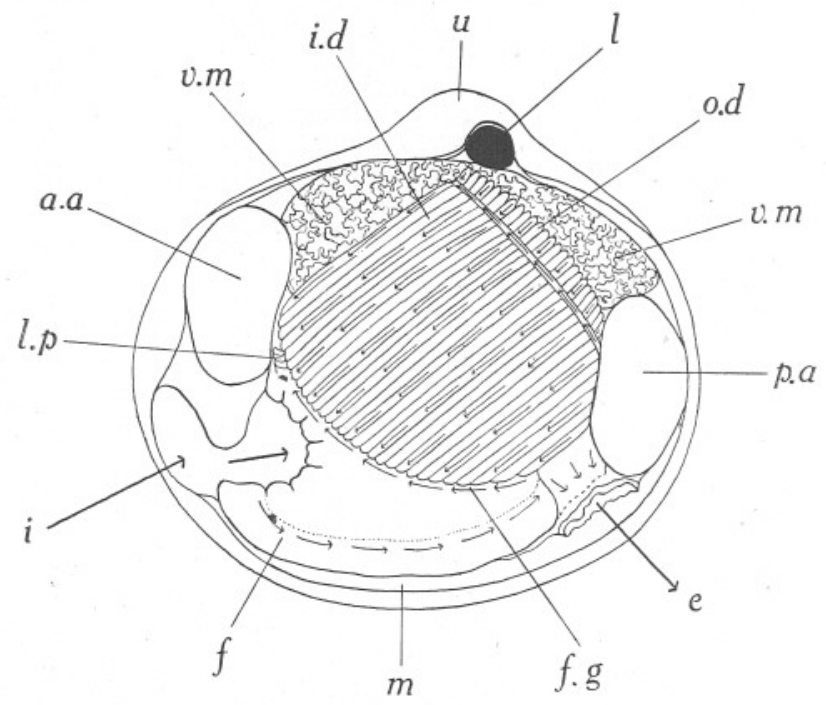

Fig. 6. L. rubra, with the left valve and mantle lobe removed to show the ciliary currents in the mantle cavity. $\times 60$. a.a, anterior adductor; $e$, exhalent current; $f$, foot; $f . g$, food groove; $i$, inhalent current; $i$.d, inner demibranch; $l$, ligament; $l . p$, labial palp; $m$, mantle; $o . d$, outer demibranch; $p . a$, posterior adductor; $u$, umbo; v.m, visceral mass.

demibranch came away with it, thus causing damage and obscuring the normal ciliary currents. The axis of the ctenidium runs diagonally. The morphologically anterior end of the axis is dorsal in position and immediately below the umbo. The morphologically posterior end is anterior to the posterior adductor, and just inside the exhalent opening (Fig. 7, c.a).

The adductor muscles are large and approximately equal in size. The posterior is rather more ventral in position (Fig. 6, a.a, p.a).

Gills. The ciliation on the inner demibranch is normal. Particles are passed down both the descending and ascending lamellae towards the free edge of the demibranch. There is a food groove along the free edge with an orally directed current (Fig. 6, f.g). On the descending lamella of the outer demibranch, in 
this case the only lamella, particles are passed up from the distal edge which is fused with the mantle, towards the axis and into the current passing forwards along the groove between the two demibranchs (Fig. 6).

Palps. There are two pairs of labial palps (Fig. 6, l.p). They are so minute that the direction of the currents over their surface could not be followed, but they certainly act in a normal manner as sorting organs and prevent large particles passing to the mouth.

Visceral mass and foot. There was also difficulty in following the currents on the surface of the visceral mass owing to the small size and the amount of damage done during dissection.

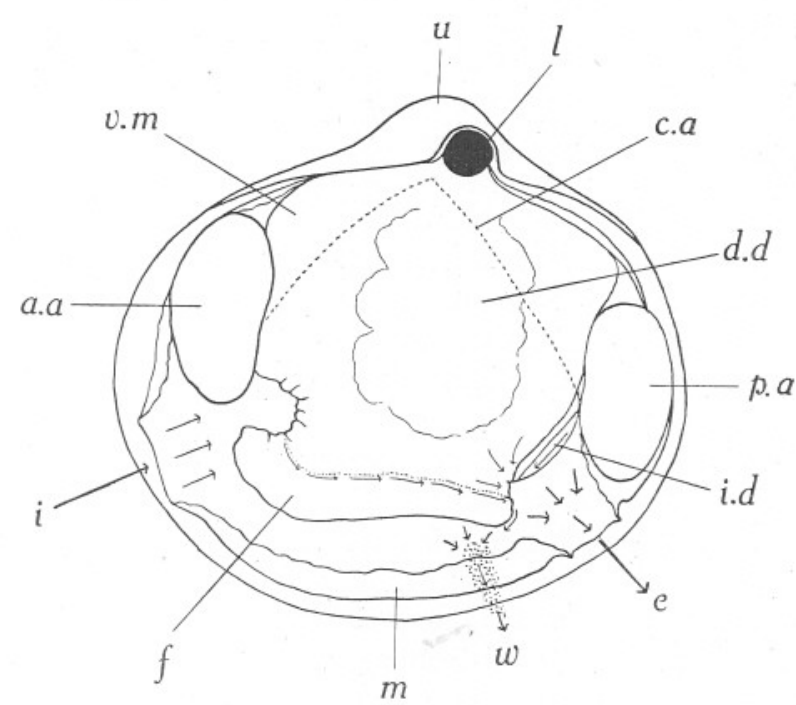

Fig. 7. L. rubra with the left valve, mantle lobe and gill removed to show the ciliary currents on the visceral mass. $\times 60$. a.a, anterior adductor; $c . a$, axis of ctenidium; $d . d$, digestive diverticula; $e$, exhalent current; $f$, foot; $i$, inhalent current; $i . d$, inner demibranch; $l$, ligament; $m$, mantle; p.a, posterior adductor; $u$, umbo; v. $m$, visceral mass; $w$, waste.

The portion of the foot which extends beyond the shell is strongly ciliated (Fig. 5,f). This is in marked contrast to Kellia. Particles are passed rapidly over the surface of the foot from the tip in a posterior direction even when it is extended. The ventral surface of the foot is most strongly ciliated. The ciliation is continued for a short distance up the sides, but there appears to be no ciliation on the dorsal surface of the foot. Only the finest particles are passed up into the mantle cavity, all larger particles are passed off the posterior portion of the foot entangled in mucus and join the main mass of waste material which is passed out behind the foot in a posterior and ventral direction (Figs. 5, 7, w).

Mantle. The ciliation of the mantle has not been determined in detail, but it appears to be normal and is concerned entirely with rejection. The main 
trend is from the anterior end in a ventral and posterior direction, i.e. in the reverse direction to the mantle currents found in Kellia. Waste material is passed out over the border of the mantle ventrally. This mass of waste material is entangled in mucus and is joined by the waste material from the foot and left behind in strings as the animal moves forward. Contractions of the free edges of the mantle surrounding the pedal opening also help in the removal of this waste material (Figs. 5, 7).

\section{Montacuta ferruginosa (Montagu)}

M. ferruginosa always occurs in association with Echinocardium cordatum. The larger specimens were found in the sand of the burrow opposite the anal siphon of the Echinocardium. There were usually several Montacuta grouped together, and the sand surrounding them was coloured reddish brown probably owing to an iron pigment among the faecal material from the Echinocardium. The red colour of the Montacuta may be due to this pigment. Some smaller specimens were found attached to the spines on the under side of the Echinocardium in a position similar to that of Montacuta substriata on Spatangus purpureus. A few specimens were collected in the muddy sand below the Marine Hotel, Salcombe, but they were not numerous, and small in size. The majority were collected from the cleaner sand at Mill Bay, Salcombe, where they are abundant.

M. ferruginosa varies greatly in size from $9 \times 4.8$ to $\mathrm{I} \cdot 5 \times \mathrm{I} \mathrm{mm}$. The shell is a light reddish brown in colour, darkest in the region of the umbo, and often almost pure white at the edge of the valves. The young specimens are the lightest in colour. The shell is oval in shape and asymmetrical, in the large specimens it is almost twice as long as it is broad. The umbo is raised slightly above the level of the hinge. The embryonic shell is still visible in the adult. The surface of the shell is smooth with faint concentric striations and the edge is entire.

The mantle edge and foot normally extend beyond the shell valves in life, but both can be completely withdrawn and there is no permanent gape between the shell valves. There is no definite inhalent siphon, but the free edges of the mantle normally extend beyond the shell anteriorly and form a temporary siphon. There are only two pallial openings. One of these is very large, extending for three-quarters of the anterior side and the whole of the ventral side except for the extreme posterior part where there is fusion of the mantle lobes for a short distance below the exhalent siphon. This large pallial opening is a combined inhalent and pedal opening and it permits a wide angle of movement of the foot. The exhalent opening is in the form of a short siphon situated on the mid-line of the posterior end (Fig. 8,e). It does not extend beyond the shell valves in life. The mantle lobes are fused dorsal to the exhalent opening.

The free edge of the mantle which extends beyond the shell and surrounds the large antero-ventral pallial opening has many papillae (Fig. 8, $p p$ ). These are small on that portion of the mantle which forms the inhalent opening and 
sides of the pedal opening, but they are larger posteriorly on the mantle surrounding the exhalent siphon, and there are two very large unpaired papillae or "tentacles", one dorsal and the other ventral to the exhalent siphon. These are very extensile. The papillae, like the mantle, are pinkish in colour, they are numerous and regular in arrangement.

The foot is large and wedge-shaped, with a thickened ventral surface used as a creeping sole (Figs. 8, 9, $f$ ), the upper part is dark red in colour, the sole is paler. The anterior end has a bluntly pointed tip which is pushed out first when the animal is moving. It seeks about and then becomes temporarily

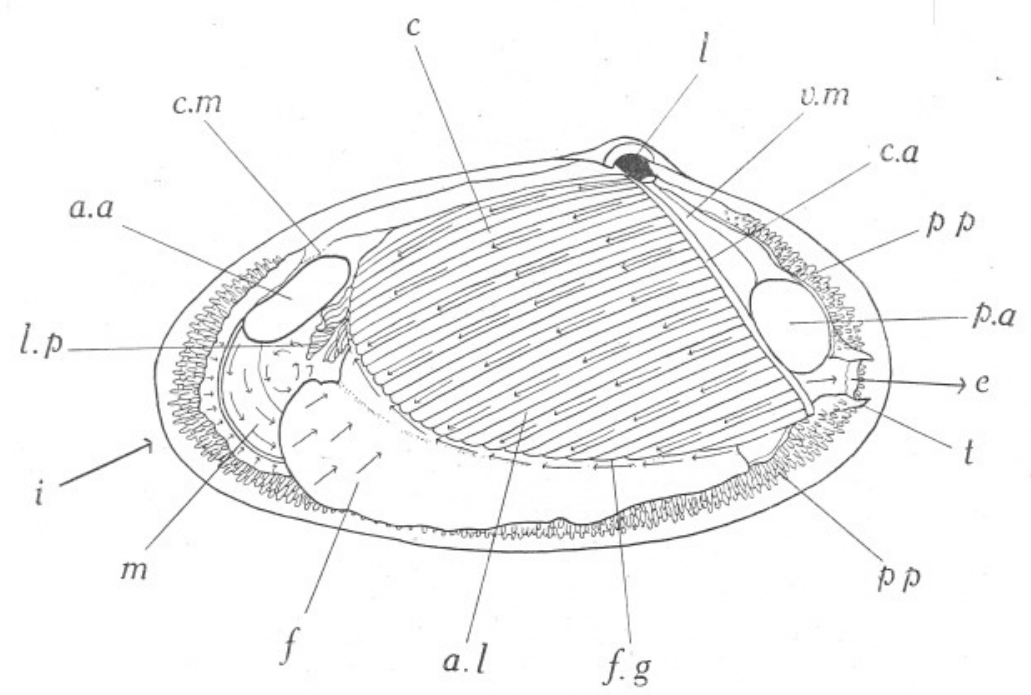

Fig. 8. Montacuta ferruginosa with the left valve and mantle lobe removed to show the ciliary currents in the mantle cavity. $\times$ IO. a.a, anterior adductor; a.l, ascending lamella; $c$, ctenidium; c. $a$, axis of ctenidium; $c . m$, cut edge of mantle; $e$, exhalent current; $f$, foot; $f . g$, food groove; $i$, inhalent current; $l$, ligament; $l . p$, labial palp; $m$, mantle; $p . a$, posterior adductor; $p p$, papillae; $t$, "tentacle"; v.m, visceral mass.

fixed down. The whole animal is tilted forward over the foot. The thin posterior part, or heel, of the foot then emerges, and the animal walks forward on the broad ventral surface of the foot, with the posterior portion trailing behind. The ventral surface of the foot is lubricated by the secretion of mucus.

The byssal gland is embedded in the posterior portion of the foot. A duct leads from it into a deep groove which runs along the ventral surface of the foot and opens out just behind the anterior tip. The young specimens are attached to the spines of Echinocardium by means of byssal threads, but the byssal gland can have little function in the adult which lives in loose sand and has no permanent attachment. None of those kept in dishes in the laboratory was seen to produce byssal threads. The adults are capable of very active movement. 


\section{Mantle cavity and ciliary currents}

There is a single complete demibranch on each side with descending and ascending lamellae (Fig. 8, c). This is the inner demibranch, the outer has disappeared completely. The axis of the ctenidium is almost dorso-ventral in position but with the upper, or morphologically anterior end of the axis slightly anterior to the lower or posterior end (Fig. 8, c.a). The axis is in this case even more vertical in position than it is in Lasaea.

The adductor muscles are well developed, the anterior is slightly larger than the posterior (Figs. 8, 9, and Io, a.a, p.a).

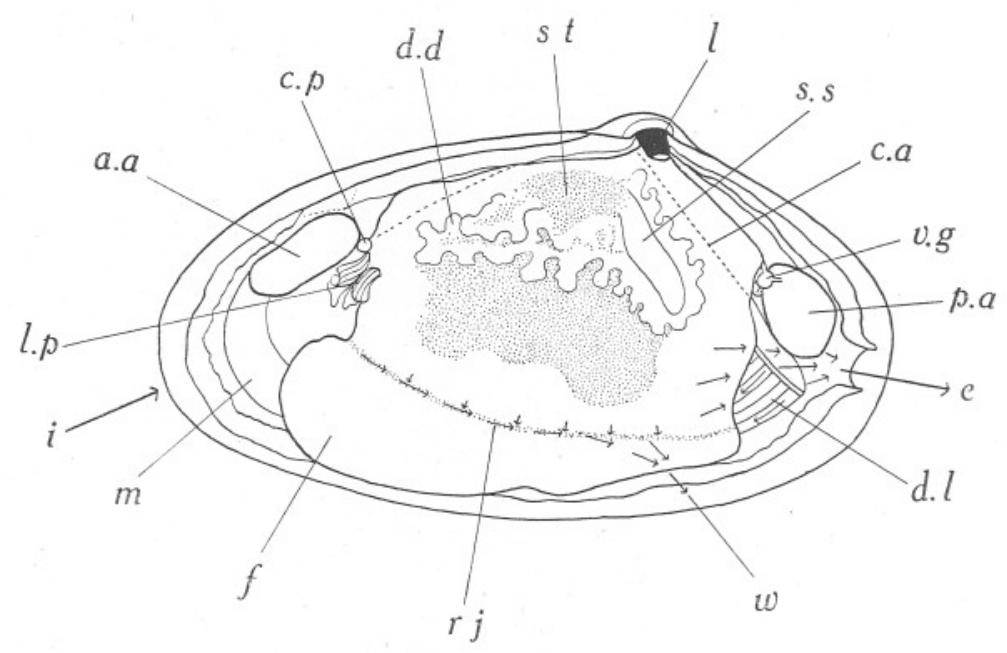

Fig. 9. M. ferruginosa with the left valve, mantle lobe and gill removed to show the ciliary currents on the visceral mass. $\times$ IO. a.a, anterior adductor; c.a, axis of ctenidium; $c . p$, cerebro-pleural ganglion; $d . d$, digestive diverticula; $d . l$, descending lamella; $e$, exhalent current; $f$, foot; $i$, inhalent current; $l$, ligament; $l$. $p$, labial palp; $m$, mantle; $p . a$, posterior adductor; $r . j$, rejection current; $s . s$, style sac; st, stomach; $v . g$, visceral ganglion; w, waste.

The whole mantle is tinged pink, and the visceral mass is dark red with greenish digestive diverticula. The ganglia are bright pink in colour and show up clearly in the mantle cavity.

Gills. The ciliation of the demibranch is normal. Particles are passed down both lamellae towards the free edge and along it to the palps and the mouth (Fig. 8, f.g).

Palps. The labial palps are relatively larger than in most members of this group (Figs. 8, 9, l.p). They are similar in appearance and ciliation to those of Kellia and appear to be quite normal in function. Only small particles are passed into the mouth. Large masses of waste material entangled in mucus are passed off the palps on to the mantle, or back along the sides of the foot and out of the mantle cavity (Fig. 9, w). 
Visceral mass and foot. There is no ciliation on the surface of the visceral mass, and only a slight ciliation causing a slow movement of particles along the sides of the foot at the level of its junction with the visceral mass (Fig. 9). This current is concerned with rejection. The particles of waste material form strings and are bound together by mucus (Figs. 9, I0, w). They are passed backwards across the foot more by the cilia on the surface of the mantle lying outside the foot and close over it than by the cilia on the foot itself.

Mantle. The actual surface of the mantle is strongly ciliated along definite tracks (Fig. IO), particularly at the anterior end. The whole of the free edge of the mantle forming the antero-ventral pallial opening is ciliated, so that

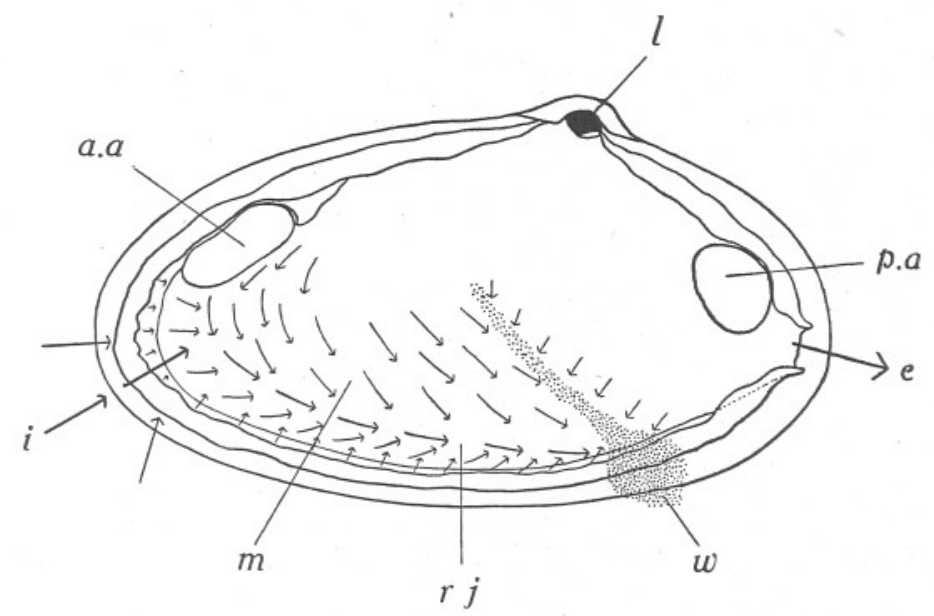

Fig. Io. M. ferruginosa. Ciliary currents on the mantle. $\times$ Io. a.a, anterior adductor; $e$, exhalent current; $i$, inhalent current; $l$, ligament; $m$, mantle; $p . a$, posterior adductor; $r i$, rejection current; $w$, waste.

particles falling on this are passed into the mantle cavity, except at the region where waste material is rejected from the mantle cavity. In this region the current is in the reverse direction. There is a band of strong cilia stretching from the mid-line of the anterior end to the posterior end of the pedal opening where the mass of waste material is passed out. It follows the curve of the shell ventrally, and a mass of waste particles and mucus is rejected behind the foot and left behind in strings as the animal moves forward. There are contributory currents on either side of the main stream, and there is a collection of particles on to one track which stretches from the centre of the mantle to a point on the ventral edge in line with the umbo. The general trend is therefore ventrally and posteriorly as in Lasaea; not anteriorly as in Kellia and most lamellibranchs (Kellogg, I9I5).

The absence of cilia on the visceral mass is probably correlated with the removal of waste material from the mantle cavity by sudden violent contractions of the whole of the free part of the mantle, aided by the contraction of the 
adductors, which has been observed at irregular intervals, apparently depending upon the amount of material entering the mantle cavity. There was no sign, however, of any removal of waste through the anterior inhalent opening as in Kellia, because the inhalent opening is closed temporarily and all waste material is shot out through the ventral pedal opening as in other members of the group. This muscular movement must be a more efficient mechanism than the gradual removal of particles by the action of cilia, as occurs in Lasaea. It is probably connected with the sandy, and often muddy environment in which Montacuta ferruginosa occurs. Kellia, which is often found in a muddy environment, has in effect a similar mechanism to prevent silting up of the mantle cavity.

\section{Montacuta substriata (Montagu)}

M. substriata is commensal with Spatangus purpureus. It was collected by dredging in shell gravel in Stoke Bay, Plymouth, and in deep water south-west of the Eddystone. It is always found attached to the spines of Spatangus and never free living. It is usually on the under side and attached to the anal spines by two or three byssal threads. Three or four may be found on one Spatangus, each attached to a different spine, but many of the Spatangus collected were without Montacuta. All the specimens collected were small, but they were fully mature.

The specimens collected varied in size from $0.6 \times 0.5$ to $\mathrm{I} .75 \times \mathrm{I} .5 \mathrm{~mm}$. The shell is whitish in colour and so transparent that the brownish coloured visceral mass is visible through the shell. There is no pigment deposited in the shell as in $M$. ferruginosa. The shell is symmetrical in comparison with other members of the group. In the smallest specimens it is only slightly longer than it is broad, and even in the largest it is only slightly asymmetrical. The umbo is prominent and raised above the level of the hinge, and the embryonic shell is clearly visible (Fig. II, $\mathrm{em}$ ). Fine lines radiate from the umbo and there are also concentric striations, presumably indicating growth stages. The shell resembles that of Kellia, but the valves are flatter and more transparent than in the adult Kellia. The edge is entire.

The free edges of the mantle do not extend beyond the shell valves and there are no definite siphons. The foot can be extended for a considerable distance, so that the portion of the foot outside the shell is greater in length than the shell, i.e. in a specimen with a shell $\mathrm{r} .5 \mathrm{~mm}$. in length, the foot was extended for a length of $2 \mathrm{~mm}$. beyond the shell, but it can be completely withdrawn and the shell valves closed.

As in $M$. ferruginosa there are only two pallial openings and there is little fusion between the mantle lobes, but in this species there are no papillae on the free borders of the mantle.

The foot is roughly cylindrical in shape, but flattened ventrally to form a creeping sole (Figs. II, I3, f). It is in two parts; the anterior is very extensile and has a rounded tip, the posterior forms a heel and trails behind. 
The animal is capable of rapid motion and exhibits a curious and characteristic rocking movement. The anterior tip of the foot is pushed out first; it can be turned about in all directions and determines the direction in which the animal travels. The tip of the foot seeks about and then becomes temporarily fastened down, apparently by a sucker-like action. The heel of the foot then appears. Muscular contractions follow, by which the animal is first tipped forwards over the point of the foot, and then rocked back so that the shell is in a normal position and the heel of the foot is in contact with the substratum. It then moves forwards by a slow gliding movement on the flat ventral surface of the foot. The violent rocking movement is repeated at irregular intervals. There is a considerable gape between the shell valves during movement. The extensive movement is possible owing to this and to the large size of the pedal opening.

The byssal gland is situated in the posterior portion of the foot, and opens into a groove on the ventral side. Two or three threads are produced and the angle separating them is not great (Fig. I , by).

\section{Mantle cavity and ciliary currents}

There is a single complete demibranch on each side consisting of a descending and an ascending lamella. As in M. ferruginosa, it is the inner demibranch. The ascending lamella is deeper than the descending, and has a supra-

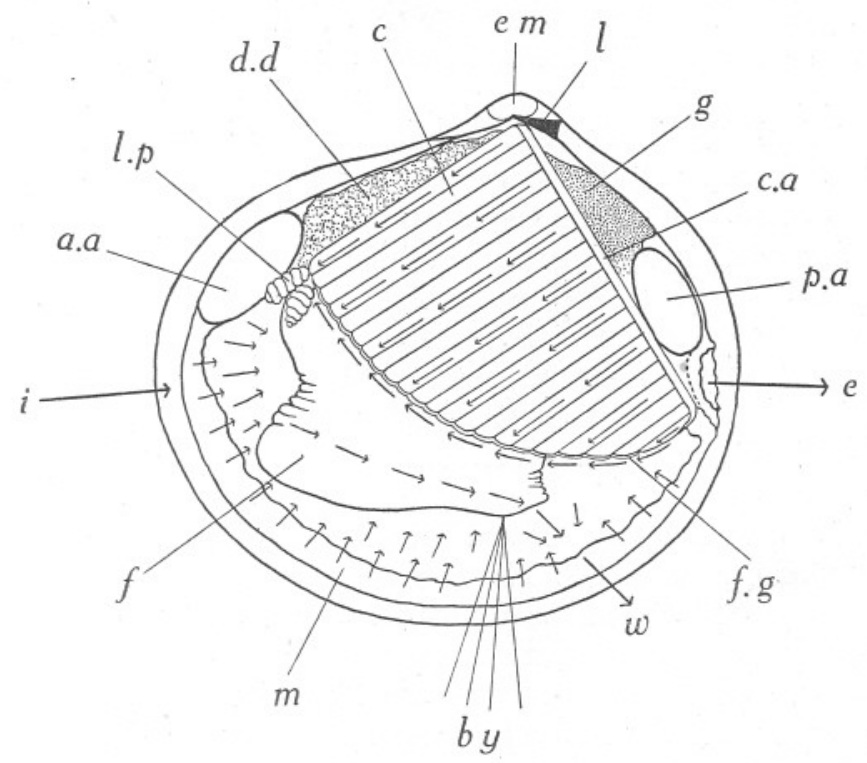

Fig. II. Montacuta substriata with the left valve and mantle lobe removed to show the ciliary currents in the mantle cavity. $\times 40$. a.a, anterior adductor; by, byssus; $c$, ctenidium; c.a, axis of ctenidium; d.d, digestive diverticula; $e$, exhalent current; $e m$, embryonic shell; $f$, foot; f.g, food groove; $g$, gonad; $i$, inhalent current; $l$, ligament; $l$. , labial palp; $m$, mantle; $p . a$, posterior adductor; $w$, waste. 
axial extension as has the outer demibranch of Kellia. The axis of the ctenidium again runs diagonally and is similar in position to that of $M$. ferruginosa (Fig. II, c.a).

The adductor muscles are well developed (Figs. II, I3 and I4, a.a, p.a).

Gills. The ciliation of the demibranch is normal (Fig. II) and the same as that found in M. ferruginosa.

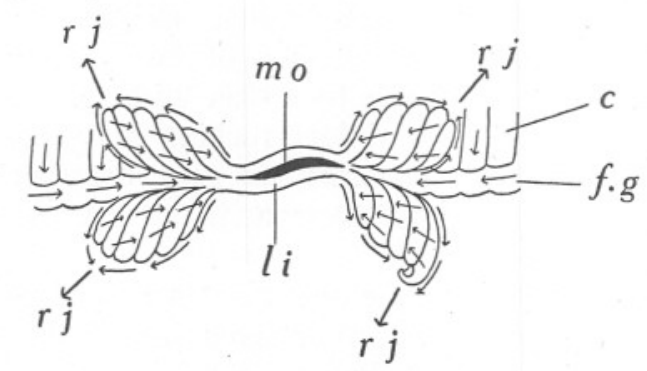

Fig. I2. M. substriata. Ciliary currents on the labial palps. $\times 80$. $c$, ctenidium; $f . g$, food groove; $l i$, lip; mo, mouth; $r j$, rejection current.

Palps. The labial palps are small, and the details of the currents on the surface were difficult to follow, but the ciliation appears to be quite normal (Fig. I2). When large quantities of waste material were being dealt with, the palps were raised so that the tips touched the overlying mantle folds, and waste material was passed off into the main rejection current passing out over the mantle surface.

Visceral mass and foot. The visceral mass is only slightly ciliated (Fig. 13). There is a movement of particles below the line of the axis of the ctenidium along the dorsal surface of the visceral mass towards the palps, and there is also some movement below this, but no definite stream of particles was observed. The surface of the foot is strongly ciliated (Figs. II, I3). Particles move rapidly across the sides of the foot from the tip to the heel, and are passed off into the main rejection current which passes out between the shell valves in a posterior and ventral direction immediately behind the foot (Figs. I3, I4, w). This current is concerned entirely with the rejection of waste material.

Mantle. There is a clearly defined band of strong cilia concerned with rejection on the mantle (Fig. I4). The free edge of the mantle surrounding the inhalent and pedal opening is also ciliated. Particles falling on this edge are passed into the mantle cavity. The area of the mantle corresponding to an inhalent siphon occupies the central part of the anterior end below the anterior adductor muscle. It is ciliated and particles are passed into the mantle cavity in this region. The ciliation is particularly strong in a line passing from the middle of the inhalent opening to a point on a level with the anterior adductor. From this point the band of cilia runs diagonally downwards and backwards to the ventral border of the mantle. This is the chief rejection area where waste 


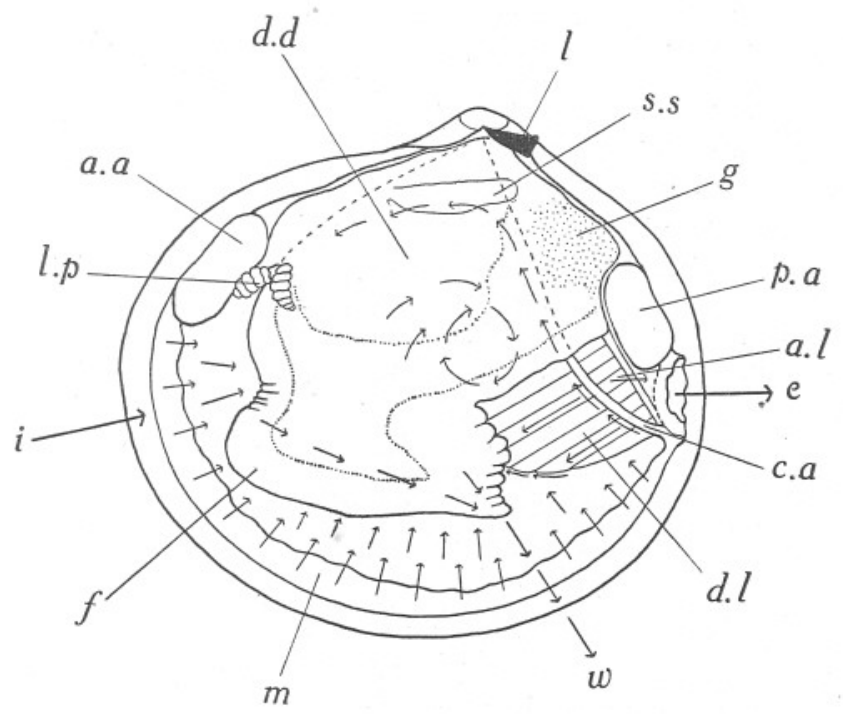

Fig. 13. M. substriata with the left valve, mantle lobe and gill removed to show the ciliary currents on the visceral mass. $\times 40$. a.a, anterior adductor; $a . l$, ascending lamella; $c . a$, axis of ctenidium; d.d, digestive diverticula; d.l, descending lamella; $e$, exhalent current; $f$, foot; $g$, gonad; $i$, inhalent current; $l$, ligament; $l . p$, labial palp; $m$, mantle; $p . a$, posterior adductor; s.s, style sac; w, waste.

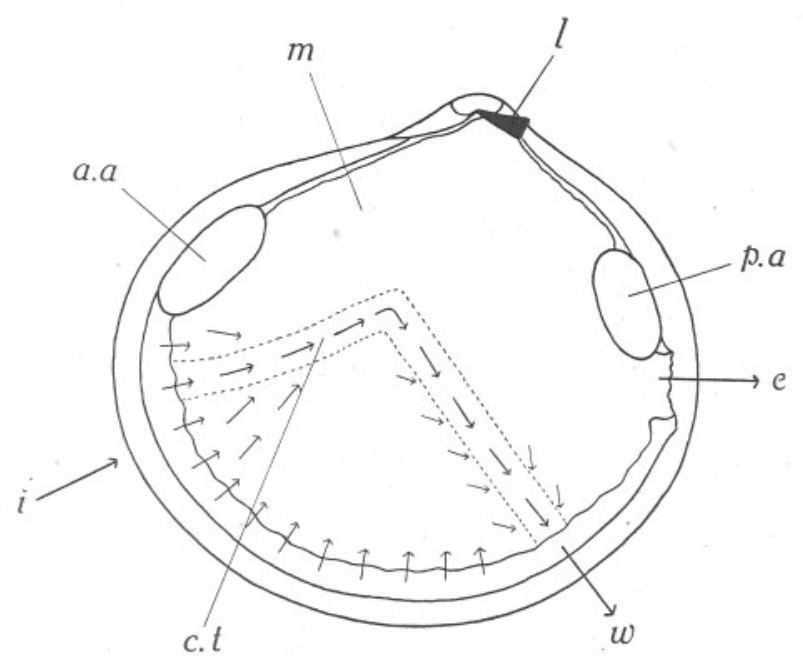

Fig. I4. M. substriata. Ciliary currents on the mantle. $\times 40$. a.a, anterior adductor; c.t, ciliated tract; $e$, exhalent current; $i$ inhalent current; $l$, ligament; $m$, mantle; $p . a$, posterior adductor; w, waste. 
material is passed out between the shell valves. The ciliation of the mantle edge is very strong at this point and particles are passed over it in the reverse direction, i.e. out of the mantle cavity instead of into it. There are slight contributory currents on the anterior side of the main stream, but the main ciliary action is confined to this definite band.

M. substriata has a most efficient ciliary mechanism for the removal of waste material and can cope with large quantities. Much waste material is passed out over the foot and never reaches the gills, while that which does reach the gills is sorted by the palps and passed out along the band of strong cilia on the mantle. The waste material is passed out entangled in mucus. The action of the cilia is assisted by sudden violent contractions of the adductor muscles, which shoot water out through the exhalent opening, and water carrying waste material out through the pedal opening. The greater part of the waste material is expelled at the normal rejection position. None was seen to pass out through the anterior end of the pallial opening in the position of the inhalent current.

\section{Mysella bidentata (Montagu)}

M. bidentata is commensal with Ophiocnida brachiata. A few were collected from the muddy shore below the Marine Hotel, Salcombe. They are rare and can only be reached at low water springs. One or two Mysella were found in the mud with each Ophiocnida, but they were never attached to it in any way. It is also reported to live in association with Phascolosoma elongatum (Winckworth, 1924; Gardiner, I928; and Salisbury, I932).

$M$. bidentata is small, the largest specimen collected measured $7 \times 5 \mathrm{~mm}$. The shell colour varies from a yellowish white to a dark reddish brown and is darkest in the region of the umbo. It is approximately rectangular in shape and only slightly rounded at each end. It is inequilateral. The surface of the shell is smooth except for concentric lines which are darker in colour than the general surface of the shell and are spaced at regular intervals.

The foot and the edge of the mantle lobes normally extend beyond the shell in life, but they can be completely withdrawn and the shell valves closed. No siphons are visible from the exterior. The free edges of the mantle have short rounded protuberances; they are blunter than the papillae of $M$. ferruginosa and are not contractile. Each has a small dark spot which gives the appearance of a row of pallial eyes.

As in both species of Montacuta, there are only two pallial openings and little fusion between the mantle lobes. There is no inhalent, and only a very short exhalent siphon.

The foot is large and wedge-shaped (Figs. $16,17, f$ ). It has a blunt tip and a flat ventral surface which is used as a creeping sole. Mysella is active and progresses by a series of violent rocking movements similar to those of Montacuta substriata (Fig. I5).

A byssal gland is present, but no byssus has so far been observed in life. No threads were produced when several specimens were kept under observa- 
tion in a dish, and it is probable that none is produced under normal conditions as the animal lives in soft sandy mud.
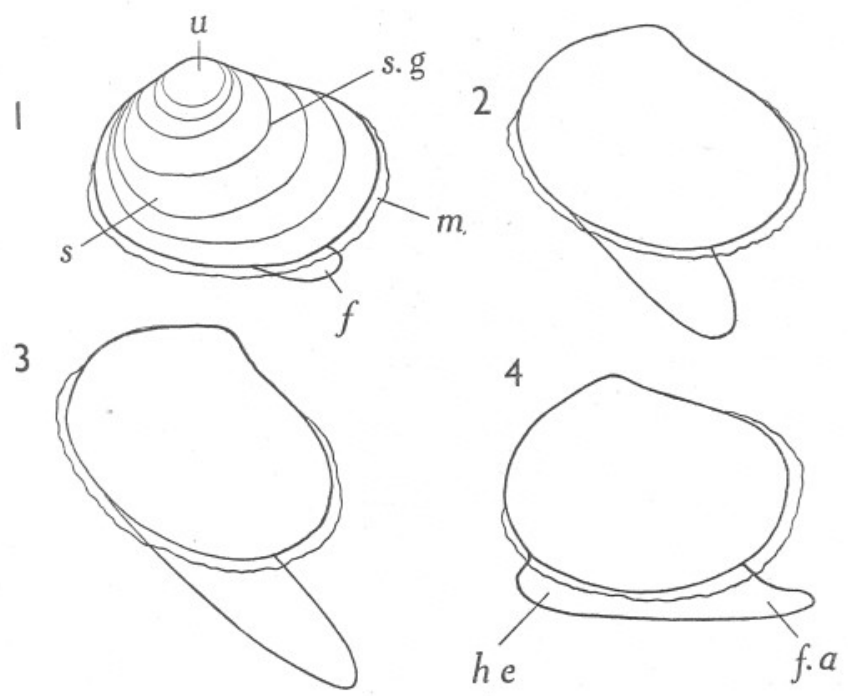

Fig. I5. M. bidentata. Four stages in movement of the living Mysella. $\times 4.5 . f$, foot; f.a, anterior portion of foot; $h e$, heel; $m$, mantle; $s$, shell; $s . g$, striations showing growth stages; $u$, umbo.

\section{Mantle cavity and ciliary currents}

There is a single complete inner demibranch, similar in position to that of Montacuta substriata, but the lamellae are deeper, i.e. the distance from the axis to the free edge is greater (Fig. I6, c).

The adductor muscles are well developed and normal in position. They are approximately equal in size, but the anterior is rounder in shape than the posterior (Figs. I6, I7, I8, a.a, p.a).

Gills. The ciliation of the ctenidia is normal and similar to that of Montacuta (Fig. I6, c).

Palps. The labial palps are small (Figs. I6, I7, l.p) and the details of the ciliary currents over the surface were difficult to follow. They were observed to function in the normal manner passing large particles off the tips into the main rejection current and fine particles only into the mouth.

Visceral mass and foot. There is an active ciliation on the surface of the visceral mass (Fig. I7). The movement of particles is most active in the region below the umbo. Strong ciliation causes a rapidly moving "whirlpool" from which particles move along two definite tracks. A strong current passes down the posterior border of the visceral mass in a straight line from below the umbo to the heel of the foot. There are contributory currents on either side of the main stream and large masses of waste material are passed out of the mantle 


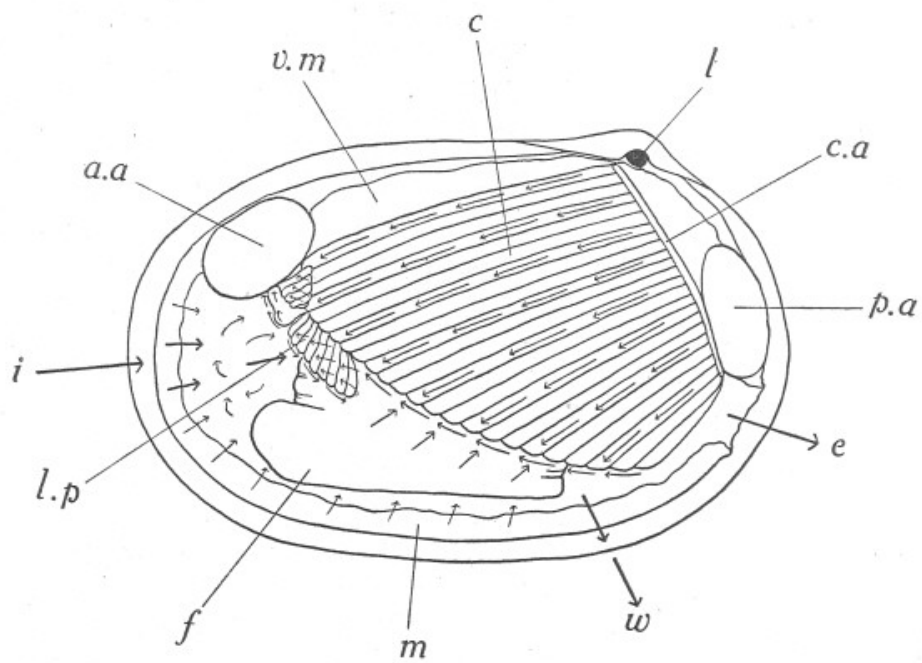

Fig. I6. Mysella bidentata with the left valve and mantle lobe removed to show the ciliary currents in the mantle cavity. × IO. a.a, anterior adductor; $c$, ctenidium; c.a, axis of ctenidium; $e$, exhalent current; $f$, foot; $i$, inhalent current; $l$, ligament; l.p, labial palp; $m$, mantle; $p . a$, posterior adductor; v.m visceral mass; $w$, waste.

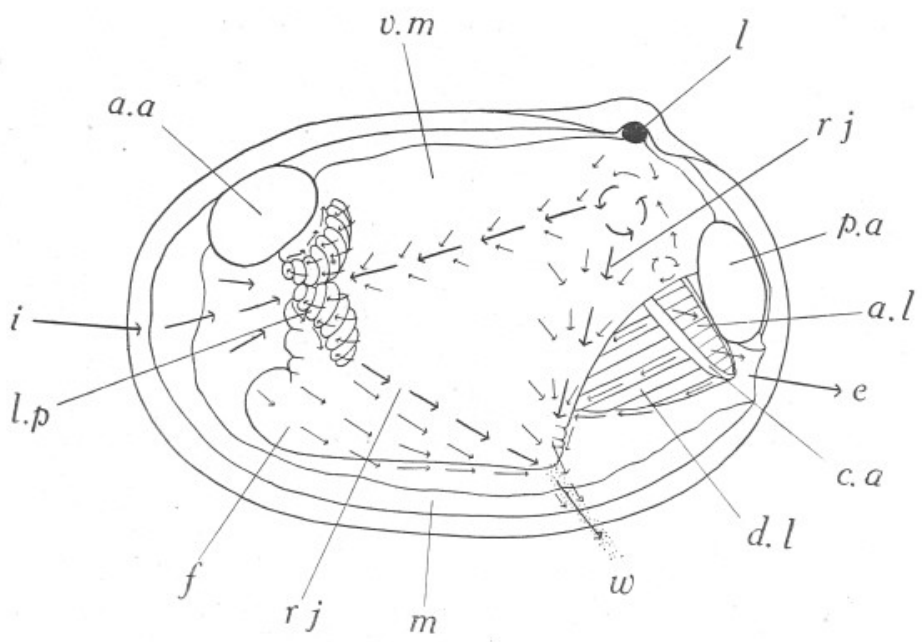

Fig. I7. M. bidentata with the left valve, mantle lobe and gill removed to show the ciliary currents on the visceral mass. $\times$ IO. a.a, anterior adductor; a.l, ascending lamella; c. $a$, axis of ctenidium; d.l, descending lamella; $e$, exhalent current; $f$, foot; $i$, inhalent current; $l$, ligament; $l . p$, labial palp; $m$, mantle; $p . a$, posterior adductor; $r j$, rejection current; v.m, visceral mass; w, waste. 
cavity immediately behind the heel of the foot. This is the rejection area (Fig. I7, w). A strong current also passes forwards from the "whirlpool" below the umbo to the labial palps. It appears to be chiefly finer particles which are passed along this track. They are sorted further by the labial palps, only the very fine particles being passed to the mouth, while the larger particles are passed into the rejection current passing along the foot. There are again contributory currents on either side of the main stream. There is also a slight movement of particles up the posterior end of the visceral mass, along the line of the axis of the ctenidium towards the umbo. These pass into one of the currents already mentioned.

There is an active ciliation on the sides of the foot. Large particles are passed off from the tips of the labial palps, diagonally backwards towards the

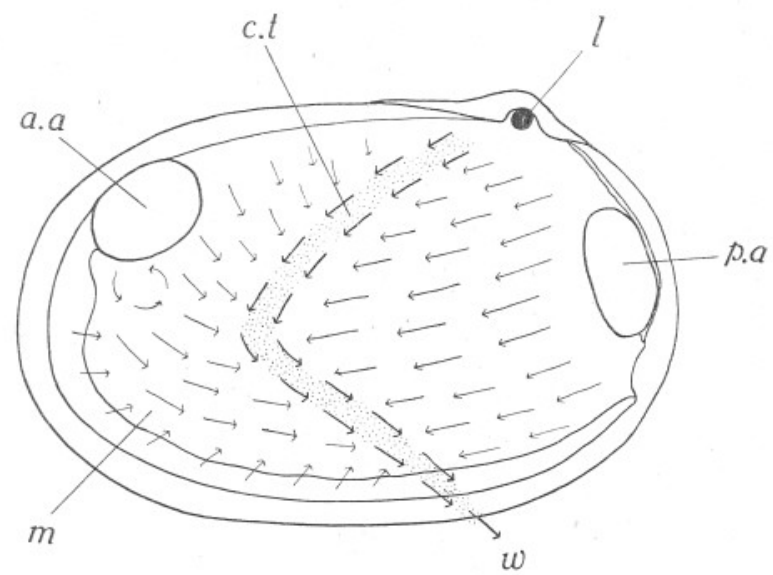

Fig. I8. $M$. bidentata. Ciliary currents on the mantle. $\times$ I0. a.a, anterior adductor; $c . t$, ciliated tract; $l$, ligament; $m$, mantle; p.a, posterior adductor; $w$, waste.

heel of the foot, where they join the stream moving down the posterior side of the visceral mass, pass out over the border of the mantle and are left behind in long strings of mucus (Figs. I7, I8, w). The whole of the sides of the foot are ciliated and particles move in the same direction as the main stream, i.e. towards the heel of the foot.

There are therefore three main currents: two of them, that along the posterior side of the visceral mass, and the current along the foot, are concerned entirely with rejection of waste material. The third current, that along the central part of the visceral mass, must also assist feeding, as the particles passed along it will be sorted by the labial palps, and any particles sufficiently fine will be passed into the mouth. This current is absent in Montacuta as is the ciliation at the posterior end of the visceral mass. The relatively larger size of the palps in Mysella may be correlated with this current supplying additional material for sorting. 
Mantle. The mantle is also ciliated over practically the whole of its surface (Fig. I8), but there is a definite strongly ciliated track from a point below and slightly anterior to the umbo, which passes downwards and forwards. It then bends sharply back, and passes diagonally backwards, reaching the ventral border of the mantle at the main rejection point exactly below the umbo. This track is even more definite than that in Montacuta substriata. It is supplied by contributory currents on either side, which collect material from the whole of the mantle surface. The free border of the mantle is also ciliated and particles falling on to it are passed into the mantle cavity. This ciliation of the mantle is concerned entirely with rejection and is the most effective mechanism of this type found in any member of the group.

This strong ciliation of the surface of the visceral mass and mantle is probably connected with the muddy environment in which the animal normally lives. Removal of waste material is not brought about by contraction of the adductor muscles and mantle as it is in $M$. ferruginosa, but the ciliary mechanism is more active and efficient in Mysella than it is in Montacuta.

\section{Devonia perrieri (Malard)}

D. perrieri is commensal with Leptosynapta inhaerens. It lives attached to the body about one-third of the distance from the anterior end of the Leptosynapta. Only one specimen was found on each, and it was attached by the foot which is flat and probably acts as a sucker when spread out over the surface. The attachment is probably assisted by the spicules in the body wall of the Leptosynapta. Devonia also crawls over the surface of the Leptosynapta using its foot as a creeping sole, but the movements were not extensive and it was never found free in the mud. No byssal threads were observed, although Devonia possesses a byssal gland.

$D$. perrieri is not common. It was collected on the shore below the Marine Hotel, Salcombe, and could only be found at low water during spring tides.

$D$. perrieri is small. The specimens collected were all about the same size, and the shell measured about $7 \times 5 \mathrm{~mm}$., but when fully expanded the same specimens measured as much as II $\times 7 \mathrm{~mm}$. The shell is white and fragile. It appears to be darker in colour in the region of the umbo owing to the colour of the visceral mass being visible through the shell. The shell is rectangular in shape and inequilateral (Fig. 19). The umbo is situated near the posterior end $(u)$. There are faint concentric striations on the surface of the shell, but no definite markings. The edge of the shell is entire.

There is a permanent ventral gape between the shell valves, and the foot and mantle normally extend beyond them (Fig. I $9, f, m$ ). The mantle extends in life for a considerable distance beyond the shell in all directions except above the hinge. It is also reflected over the outer surface of the shell for a short distance on all sides except in the region of the hinge $(m . s)$.

There are two pallial openings as in Montacuta and Mysella, but there is fusion between the two mantle lobes to a greater extent. The mantle extends 
for a considerable distance beyond the shell anteriorly and forms a "hood" over the inhalent opening (Fig. I9, ho). There is no permanent siphon, but a temporary siphon is formed by the edges of the mantle coming together above the foot and separating the inhalent from the pedal opening. The free edges of the mantle are turned back round this opening. The portion of the anteroventral opening corresponding to the pedal opening is small, as the mantle lobes are fused for the posterior two-thirds of the ventral side. This must restrict the movement of the foot to some extent. The exhalent opening is very

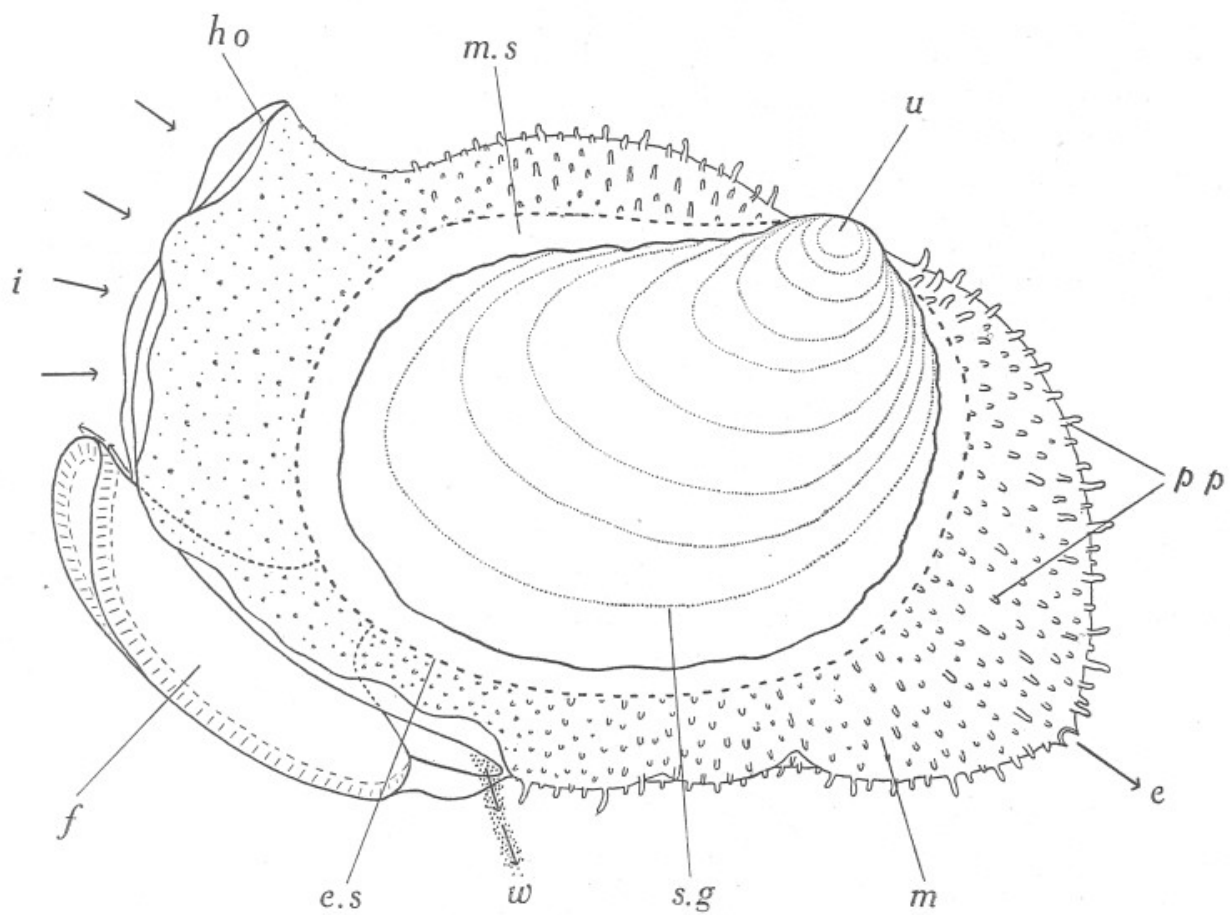

Fig. I9. Devonia perrieri. External appearance. $\times$ Io. e, exhalent current; e.s, edge of shell; $f$, foot; ho, hood; $i$, inhalent current; $m$, mantle; $m . s$, mantle covering shell; $p p$, papillae; s.g, striations showing growth stages; $u$, umbo; $w$, waste.

small. It is situated at the postero-ventral extremity of the mantle. Its position varies with the amount of extension of the mantle, but it is normally some distance beyond the shell. It is a small circular opening which can be closed by contraction of the mantle (Fig. I9, e). The mantle lobes are fused dorsally and for the whole of the posterior side except for the exhalent opening.

The surface of the whole of the mantle lobes which extends beyond the shell is covered with papillae (Fig. I9, $p p$ ). These are irregularly arranged and vary in size. They are largest on the posterior and ventral portions of the shell, and small on the lobes which form the inhalent siphon. There are none on the narrow band of mantle which is reflected over the outer surface of the shell. 
The foot is cylindrical in shape near the visceral mass, but it is flattened out into a broad triangular disk anteriorly (Figs. I9, 20, $f$ ). The shape and movement of the foot are characteristic of this species. The foot is very large and can be greatly extended; the flattened triangular part is spread out over the body surface of the Leptosynapta and probably acts as a sucker. When fully extended this flattened part of the foot exceeds the size of the whole animal. The central part of the foot is thick and the gonad extends into it. The edges of the foot are thinner and indented. The indentations fit into the irregularities of the body wall of the Leptosynapta. The foot can be turned about in all directions when the animal is moving. It was never seen in life with the foot completely withdrawn between the lobes of the mantle.

A byssal gland is situated in the posterior portion of the foot and opens by a pore on the ventral surface of the anterior portion of the foot, but no byssus was observed in life. The sucker-like action of the foot is probably sufficient for attachment, assisted by the spicules of the Leptosynapta. According to Anthony (I9I6), however, Devonia is attached to Synapta by byssal threads which leave a scar on the body wall, but none of the Devonia personally collected was attached in this way, and did not produce any byssal threads while under observation.

\section{Mantle cavity and ciliary currents}

There is a single complete inner demibranch on each side. The ascending lamella is larger than the descending and extends dorsally in a supra-axial extension (Figs. 20, 2I, c). The axis of the ctenidium is vertical (Fig. 20, c.a).

The adductor muscles are small (Figs. 20, 21, a.a, p.a). The anterior adductor is not only small but is situated at the antero-dorsal edge of the shell, almost on a level with the hinge and cannot be very effective.

Gills. The ciliation of the demibranch is normal (Fig. 20, c).

Palps. The labial palps are very small, but the ciliation appeared to be quite normal (Fig. 2I, l.p).

Visceral mass and foot. There is some ciliation on the surface of the visceral mass, and particles pass from below the umbo in two streams (Fig. 2I). One is forwards along the dorsal side towards the palps, where the particles are sorted, most being passed into a rejection current down the anterior border of the visceral mass, only the very finest being passed from the palps into the mouth. Particles also pass in a stream down the posterior border of the visceral mass and forwards along the ventral border to the foot. The ciliation is slight and neither of these currents is strong. They are concerned chiefly with rejection, although there may be some additional feeding from the current passing to the palps.

The ciliation of the foot is active (Figs. 20, 2I, f). Waste material is passed along the cylindrical part of the foot from the visceral mass towards the tip and out along two definite tracks. One is up the dorsal side of the proximal end of the anterior part of the foot and out below the inhalent stream over the 


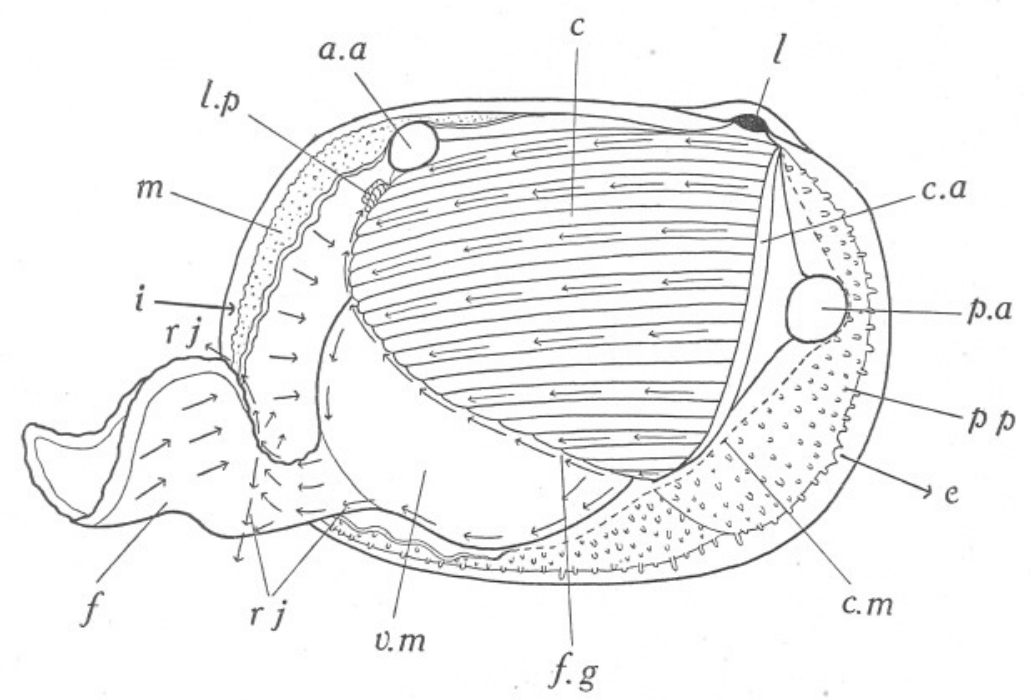

Fig. 20. D. perrieri with the left valve and mantle lobe removed to show the ciliary currents in the mantle cavity. $\times$ IO. a.a, anterior adductor; $c$, ctenidium; $c . a$, axis of ctenidium; $c . m$, cut edge of mantle; $e$, exhalent current; $f$, foot; $f . g$, food groove; $i$, inhalent current; $l$, ligament; $l . p$, labial palp; $m$, mantle; $p . a$, posterior adductor; $p p$, papillae; $r j$, rejection current; v.m, visceral mass.

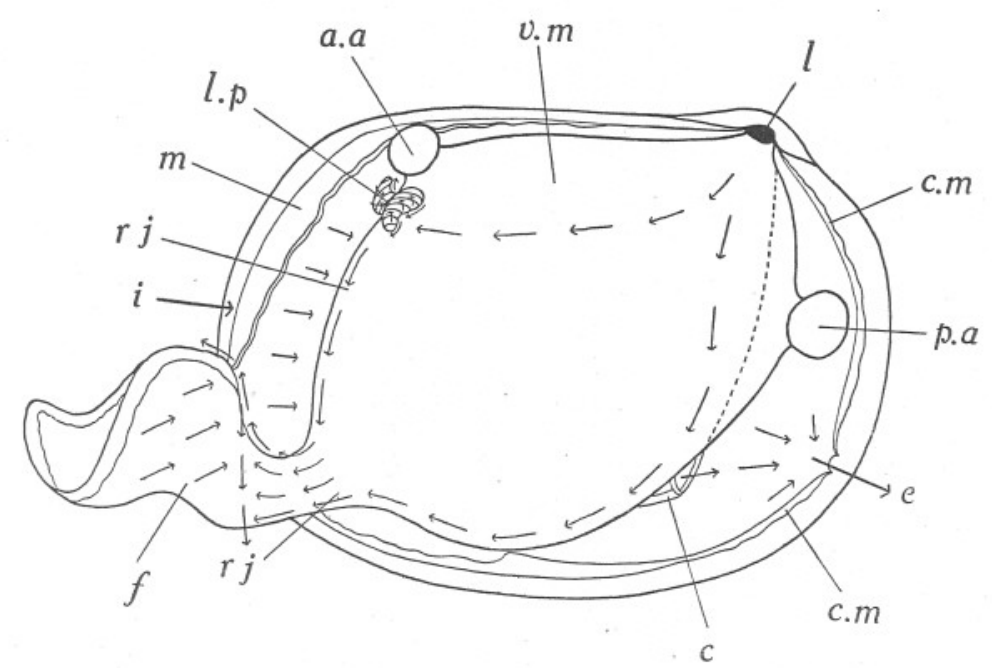

Fig. 2I. D. perrieri with the left valve, mantle lobe and gill removed to show the ciliary currents on the visceral mass. $\times$ Io. $a . a$, anterior adductor; $c$, ctenidium; $c . m$, cut edge of mantle; $e$, exhalent current; $f$, foot; $i$, inhalent current; $l$, ligament; l.p, labial palp; $m$, mantle; $p . a$, posterior adductor; $r j$, rejection current; $v . m$, visceral mass. 
raised central part of the foot. It is separated from the inhalent current by the mantle edges, which come together and form a temporary siphon above it. The other is a ventrally directed stream in which waste material is passed out behind the foot at the posterior end of the pedal opening (Fig. 19, w). The whole of the ventral surface of the anterior portion of the foot is ciliated. Particles are passed from the anterior end back into one of the main streams. The edges of the triangular anterior part of the foot may be turned up so that waste particles are passed on to the dorsal surface of the foot and out in the dorsally directed current, or they may pass along the ventral surface and into the ventral current. Waste material is passed out entangled in mucus.

Mantle. The currents on the mantle were not examined thoroughly as the animals were too much damaged during dissection for complete observations of the ciliary currents, but there appeared to be some ciliation of the mantle surface which assisted in the removal of waste material in the two streams mentioned above. Most of the waste material is probably removed by the mantle currents, as the visceral mass is only slightly ciliated.

\section{Galeomma turtoni Sowerby}

G. turtoni is free living. It was collected by dredging in Stoke Bay, east of the Mewstone, Plymouth. Several specimens were found crawling on the surface, in the crevices of the red rock, in a position similar to that of Kellia suborbicularis, or in the holes bored in it by Pholadidae, Saxicava, etc. It is

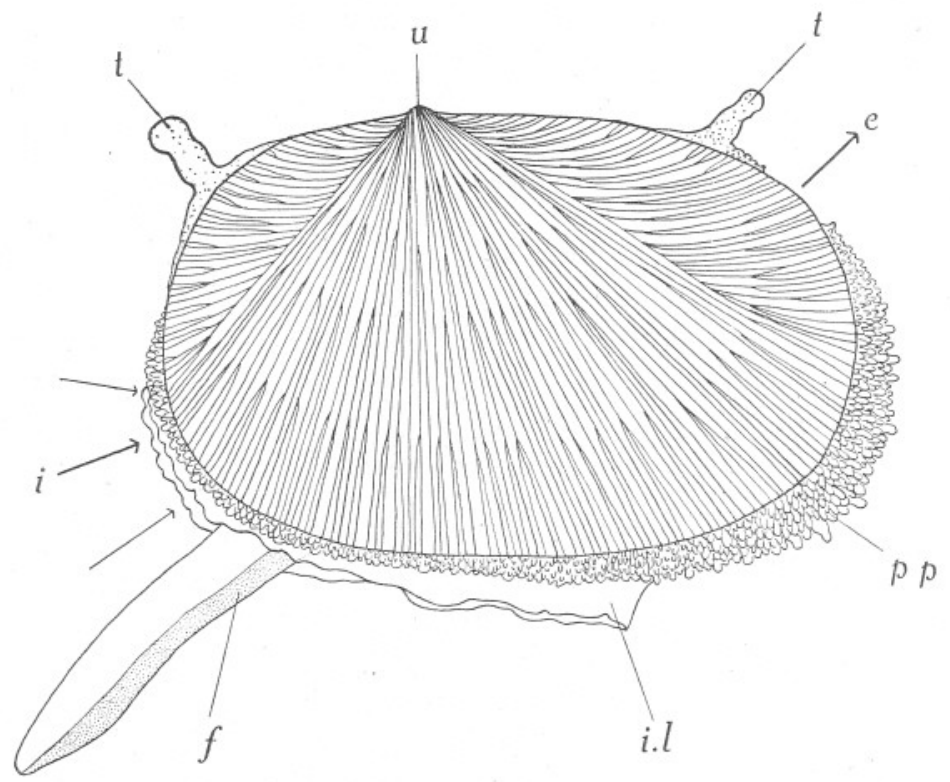

Fig. 22. Galeomma turtoni. External appearance, lateral view. $\times$ ro. $e$, exhalent current; $f$, foot; $i$, inhalent current; $i . l$, inner mantle lobe; $p p$, papillae; $t$, "tentacle"; $u$, umbo. 
capable of active movement, crawling about on its foot, but it is often found attached to the rock by several fine byssus threads. In this case the animal is usually found suspended by the byssus, with the hinge hanging ventrally and the valves spread wide apart. When moving about, however, the hinge line is in the normal position, that is dorsal, with the foot extended ventrally.

The size of the shell of the specimens collected varied from $6.5 \times 3.25$ to I $2 \times 5 \mathrm{~mm}$., and the whole animal was slightly larger when the mantle was fully expanded. The shell is pure silvery white in colour and fragile. It is never pigmented, and the whole animal is pure white except for the dark greenish mass of the digestive diverticula. The shell is rectangular in shape (Fig. 22). The surface of the shell is covered with fine raised lines which radiate from the umbo and branch towards the periphery. These raised ridges give a "lattice-work" effect as the shell is practically transparent between them. There are also two lines on either side of the umbo more prominent than the rest, which give the appearance of two lateral wings. The whole shell valve is almost flat, and when seen from the exterior the valves are only slightly convex. The umbo is raised slightly above the hinge line. The hinge is simple, practically straight, with no hinge teeth (Fig. 24, $h$ ).

There are two pallial openings. The inhalent-pedal opening is larger than it is in Devonia and extends for two-thirds of the ventral side (Fig. 22). The exhalent opening is also larger than in Devonia, it is situated postero-dorsally, and is in the form of a distinct siphon (Fig. 24,e).

The free borders of the mantle are greatly enlarged. The inner mantle fold (Yonge, I936) is produced laterally and is fused with the corresponding lobe from the opposite side behind the pedal opening (Fig. 23, f.m). The fusion of the mantle is complete for the posterior third of the ventral side and for the whole of the posterior end except in the region of the exhalent opening (Fig. 22). Anteriorly there is fusion between the mantle lobes only for a short distance above the inhalent opening. The middle mantle fold has a thickened band round the edge of the shell valves and this bears numerous regularly arranged papillae. There are no papillae on the inner mantle fold which is produced laterally, it is smooth and very contractile. The free edges of the fold which form the borders of the inhalent and pedal openings are "frilled" (Fig. 23); they can be closed down on to the sides of the foot and thus close the inhalent opening temporarily although the foot can never be withdrawn completely within the mantle cavity. There are also two very large papillae, or "tentacles" on the dorsal part of the mantle at either side of the hinge (Figs. 22, 24, $t$ ). They are capable of considerable extension and are probably sensory in function, as they contract when touched. The outer mantle fold produces the shell. It is normal in function and in position, lying close under the shell.

The foot is large. It is divided into an anterior and posterior part by a deep transverse groove (Figs. 23, 24, $f$ ). The anterior portion is cylindrical in shape, capable of great extension, and even in the contracted condition it comprises 
the greater part of the foot. The posterior portion is short and rounded and contains a large byssal gland (Fig. 24, b.g).

The anterior tip of the foot is pushed out in a ventral direction when the animal starts to move and it can be twisted and turned about in all directions. It becomes temporarily fixed to the substratum, the posterior part of the foot then appears and the animal moves forwards on the flattened ventral surface of the whole foot, which forms a creeping sole. The posterior part forms the

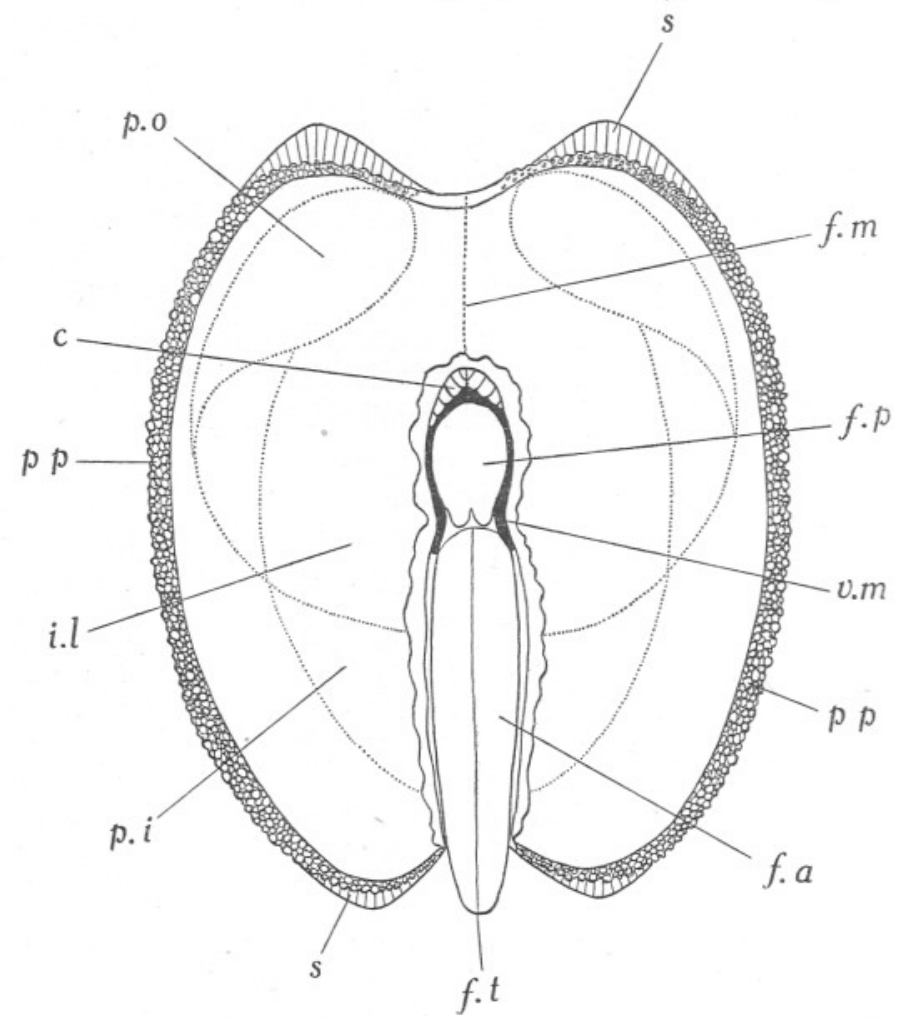

Fig. 23. G. turtoni. External appearance, ventral view. $\times$ Io. $c$, ctenidium; f.a, anterior portion of foot; f.m, fusion of mantle; f.p, posterior portion of foot; f.t, tip of foot; i.l, inner mantle lobe; $p . i$, position of inner demibranch; $p . o$, position of outer demibranch; $p p$, papillae; $s$, shell; $v . m$, visceral mass.

heel; it is compact and does not trail behind. The byssus is produced at the extreme posterior end of the foot, this region being dense white in colour owing to the presence of a large byssal gland. Only two or three threads are produced, these are white in colour and fine, but very strong. The animals were often found suspended from the rock by the byssus with the hinge line downwards, and when kept under observation in a finger bowl the animals were seen to climb up the sides of the bowl moving on the flat ventral surface formed by the foot and the fused mantle folds (Fig. 23). (When in this position 
there is a wide ventral gape between the shell valves, and the mantle is fully extended.) Two or three byssal threads were then produced from the posterior end of the foot, by which the animal attached itself to the side of the bowl. The animal then hung suspended by these threads with the foot contracted and the flat ventral surface uppermost. The shell valves are drawn together when in this position, but there is always a considerable gape between them. The free edges of the mantle surrounding the inhalent and pedal openings closed down on to the sides of the foot, and the whole mantle contracted.

\section{Mantle cavity and ciliary currents}

There are two complete demibranchs on each side; the outer is smaller than the inner and does not extend so far ventrally (Fig. 24). The axis of the ctenidium runs diagonally backwards from below the umbo (Fig. 26, c.a).

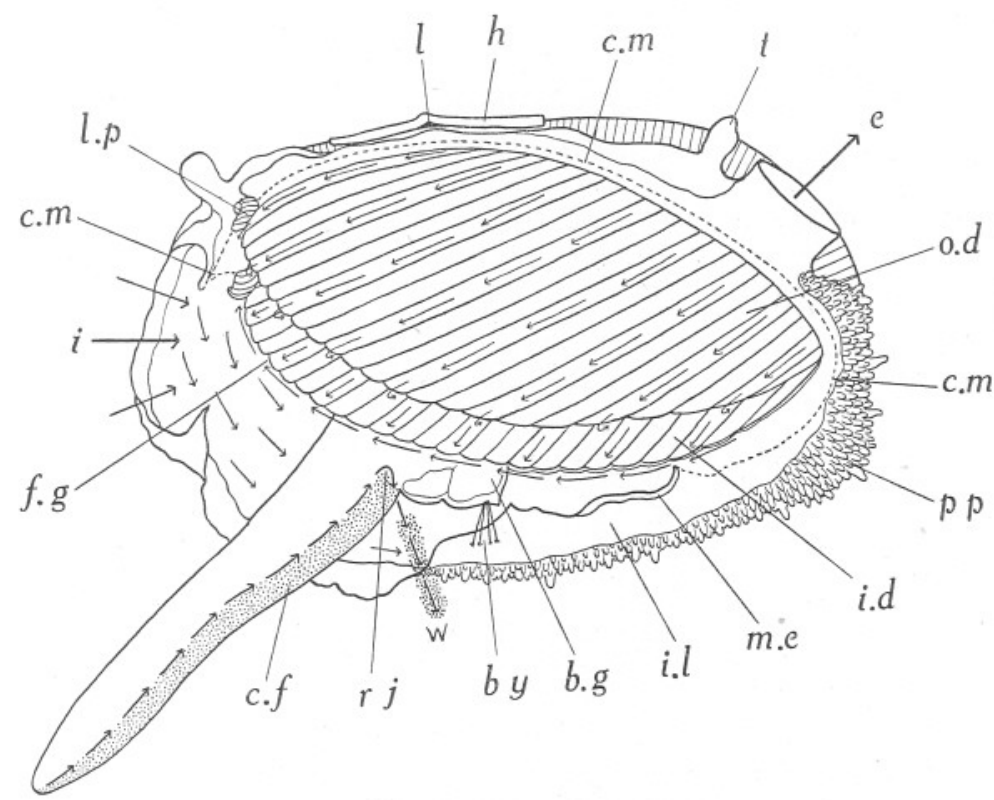

Fig. 24. G. turtoni, with the left valve and mantle lobe removed to show the ciliary currents on the visceral mass. $\times$ Io. $b . g$, byssal gland; by, byssus; c.f, ciliated portion of foot; $c . m$, cut edge of mantle; $e$, exhalent current; f.g, food groove; $h$, hinge; $i$, inhalent current; $i . d$, inner demibranch; $i . l$, inner mantle lobe; $l$, ligament; l.p, labial palp; m.e, mantle edge; o.d, outer demibranch; $p p$, papillae; $r j$, rejection current; $t$, "tentacle"; $w$, waste.

The adductor muscles are small (Fig. 26, a.a, p.a). The posterior adductor is larger than the anterior. Both are situated near the dorsal side of the shell and they probably have little function as there is only slight movement of the shell valves.

Gills. The ciliation of the gills is similar to that in Kellia suborbicularis. The outer demibranch is normal; particles are passed down both the descending 
and ascending lamellae and along the food groove at the distal edge towards the labial palps and the mouth. On the outer demibranch, however, particles pass down from the proximal to the distal edge on the outer or ascending lamella, in under the free edge and up the descending lamella towards the axis. There is, therefore, no food groove at the distal edge of the outer demibranch (Fig. 24). There is an orally directed axial current between the demibranchs.

Palps. The labial palps are relatively small, but as $G$. turtoni was the largest species to be examined the ciliary currents on the labial palps were examined in detail (Fig. 25). The ciliation is similar to that of Kellia and is quite normal. There appeared to be more movement of particles on the actual lips of the

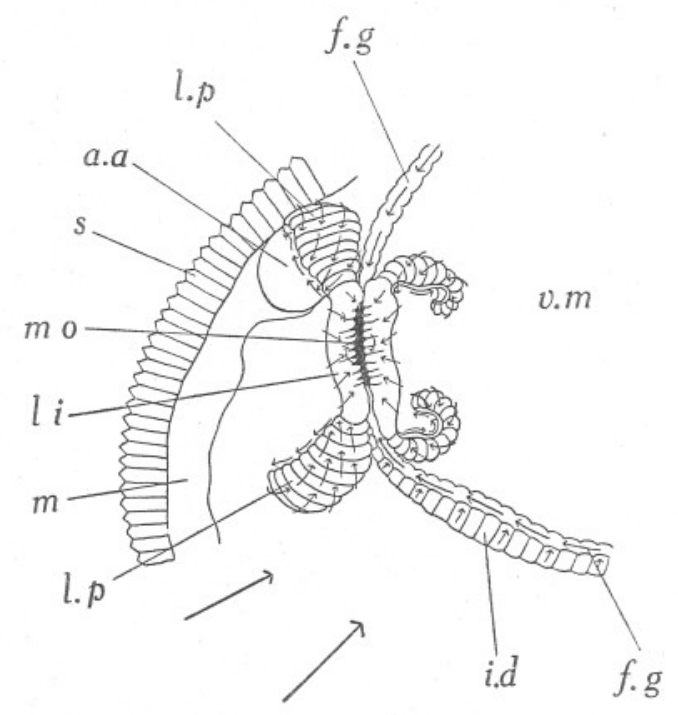

Fig. 25. G. turtoni. Ciliary currents on the labial palps. $\times 25$. a.a, anterior adductor; f.g, food groove; $i . d$, inner demibranch; $l i$, lip; $l . p$, labial palp; $m$, mantle; mo, mouth; $s$, shell; $v . m$, visceral mass. Large arrows indicate direction of part of main inhalent current.

mouth than in Kellia (Fig. 25, li). Only very fine particles are passed into the mouth, these are revolved slowly and mixed with mucus before being taken in. Large particles are passed off the tips of the palps forming long strings of waste material entangled in mucus.

Visceral mass and foot. The surface of the visceral mass is ciliated. Particles are passed slowly forwards over the whole surface from the posterior border towards the labial palps (Fig. 26). The strongest current is along the line of the axis, where the ascending lamella of the inner demibranch is fused with the visceral mass (c.a).

There is also an active ciliation on both the lateral and ventral surfaces of the foot (Fig. 26, c.f). Particles are passed up from the tip towards the base and are passed off the foot in a ventral direction at the level of the groove 
dividing the anterior part of the foot from the posterior $(w)$. The chief rejection of waste material occurs here. Strings of mucus with waste material are passed out of the mantle cavity at the posterior end of the pedal opening (Figs. 24, $26, w)$ and left behind in a sticky mass. There is a band of strong cilia up either side of the foot, forming a definite lateral line. The whole of the ventral surface of the foot is also ciliated, but there is no ciliation on the dorsal surface (Figs. 24, 26).

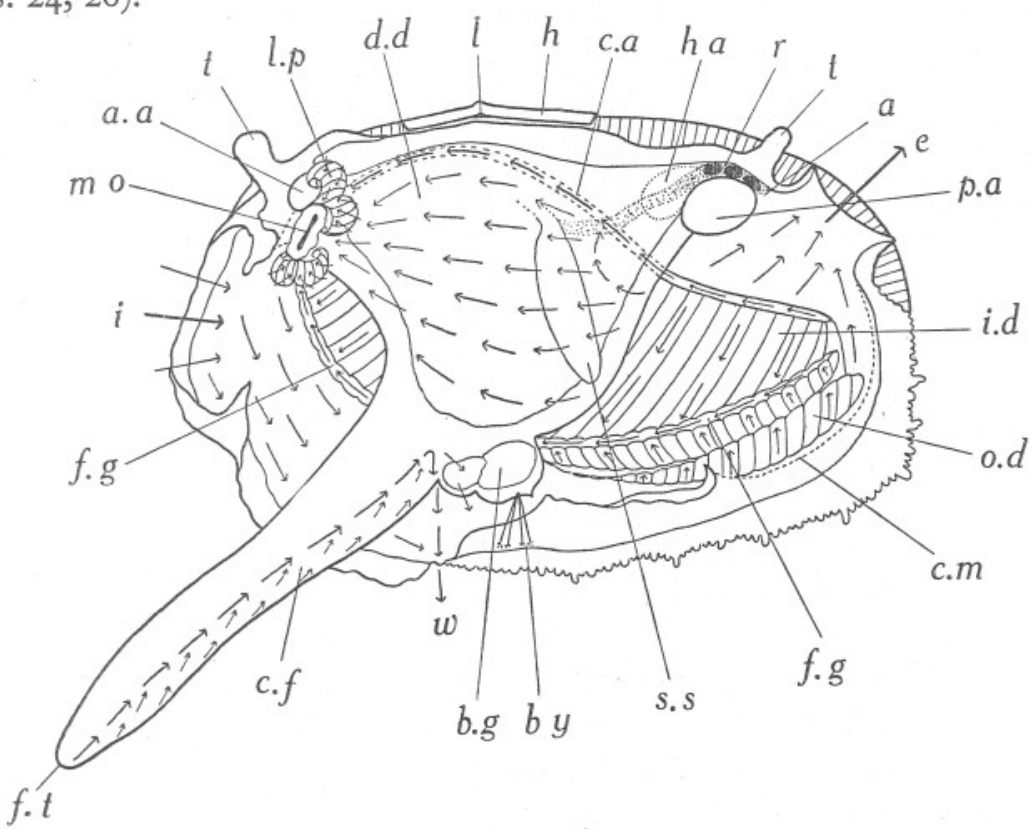

Fig. 26. G. turtoni, with the left valve, mantle lobe and gill removed to show the ciliary currents on the visceral mass. $\times$ Io. $a$, anus; $a . a$, anterior adductor; $b . g$, byssal gland; by, byssus; c.a, axis of ctenidium; c.f, ciliated portion of foot; c.m, cut edge of mantle; $d . d$, digestive diverticula; $e$, exhalent current; $f . g$, food groove; f.t, tip of foot; $h$, hinge; $h a$, heart; $i$, inhalent current; $i . d$, inner demibranch; $l$, ligament; $l$. $p$, labial palp; mo, mouth; $o . d$, outer demibranch; p.a, posterior adductor; $r$, rectum; s.s, style sac; $t$, "tentacle" ; $w$, waste.

Mantle. There was apparently little ciliation on the actual surface of the mantle, but it was difficult to see because the mantle contracts at once when touched, and remains contracted when the visceral mass is removed. Also, the inner fold of the mantle obscures the rest of the inner surface of the mantle lobe, so that it cannot be seen even when partially dissected. The only currents observed were caused by ciliary action on the ctenidia and not by cilia on the mantle. No definite bands of cilia could be seen by transmitted light as in Montacuta substriata and Mysella bidentata, but the removal of waste is helped by sudden and irregular contractions of the adductors and mantle, by which water carrying waste material is shot out through the pedal and inhalent openings. In this it resembles Kellia suborbicularis, but in this case the majority 
of waste material passes out through the pedal, and not the inhalent opening, although some passes out of the anterior end of the opening which corresponds to the inhalent opening. The lack of ciliation of the mantle is probably correlated with the sudden violent movements which remove waste material, instead of the steady stream caused by ciliary action as seen in Mysella bidentata.

\section{Discussion}

The British fauna contains representatives of the families Erycinidae, Montacutidae and Galeommatidae, which are of especial interest because they exhibit various stages in the progressive adaptation from the free-living condition (e.g. Kellia) to extreme modification for a commensal mode of life (e.g. Devonia) which is characteristic of the order Leptonacea. These modifications involve (I) reduction in the shell, (2) modification of the foot as a means of creeping, (3) change in direction of the flow of water through the mantle cavity, (4) change in the site and manner of expulsion of waste material from the mantle cavity. With all of these this paper is concerned, though especially with the last two. They also involve (5) incubation of the larvae to a relatively advanced state of development within the mantle cavity.

Kellia, Lasaea, Montacuta, and Mysella all have external shells and welldeveloped adductor muscles, and although the siphon, foot and mantle border may normally extend beyond the shell valves they can be withdrawn and the shell valves closed. There is, however, a reduction of the shell in Galeomma with an accompanying loss of hinge teeth and poor development of adductor muscles and also a permanent gape between the shell valves; the mantle and foot extend beyond them and cannot be withdrawn. Of the British species, the greatest reduction of the shell occurs in Devonia, in which not only is the shell reduced in size, but it is partly covered by the mantle. There is a ventral gape and the foot, siphons and mantle permanently extend for a considerable distance beyond the shell valves. The adductors are relatively smaller than in Galeomma and can have little function. The shells of Galeomma and Devonia are fragile as well as reduced in size. An extreme case is found in Phlyctaenachlamys lysiosquillina, an Australian species of the Galeommatidae, in which the shell is even more reduced in size and completely enclosed in the mantle (Leyborne Popham, 1939).

All members of this order have developed a creeping habit and the foot is modified to form an efficient creeping organ. Lasaea and Mysella especially are capable of rapid movement on the flattened ventral surface of the foot. The foot is also used as a means of attachment. Byssal glands are present in all the species examined, and byssus threads were observed in Kellia, Lasaea, Montacuta substriata, Galeomma, and in young specimens of M. ferruginosa. None was seen in Mysella which is not attached to its "host", nor in Devonia, but in this case the flattened foot probably acts as a sucker and serves as a means of attachment, as well as acting as a creeping organ. 
Throughout this group the respiratory and feeding current passes through the mantle cavity from anterior to posterior, i.e. the inhalent opening is not posterior as it is in the remainder of the Eulamellibranchia. This represents a reversion to the primitive molluscan condition which is still retained in the Loricata (Yonge, I939 $a$ ) and in the families Nuculidae and Solenomyidae of the Protobranchia though not in the Nuculanidae (Yonge, I939 b). This reversion may reasonably be associated with the loss of the burrowing habit in this order and with modification of the foot which has also re-acquired the properties of that of the primitive Mollusca.

With the exception of Kellia, the least specialized of the genera, where it is expelled by way of the inhalent siphon as in the great majority of the other Eulamellibranchia, waste material is removed ventrally from the mantle cavity. In Devonia it is passed out both ventrally and also below the inhalent current at the anterior end. This is probably due to the fact that Devonia normally lives attached to Leptosynapta and, when the foot is contracted, the free portion of the pedal opening behind the foot through which the waste matter is normally removed is very small, or closed completely when the mantle edges are in contact with the body-wall of the "host".

As has already been observed, the method of removal of waste through the ventral opening varies. This is correlated with the reduction of the shell and the development of a considerable amount of muscle in the mantle. It is seen in an advanced stage in Phlyctaenachlamys lysiosquillina, in which not only is waste matter removed but movement is assisted by forcing water out from the mantle cavity by sudden violent contractions of the mantle (Leyborne Popham, I939). In Lasaea waste material is removed by ciliary action on the mantle aided by muscular contractions of the mantle border. In Montacuta substriata it is due partly to ciliary action of the foot, visceral mass and mantle, but chiefly to sudden contractions of the adductor muscles which are well developed in this species. In $M$. ferruginosa there is no ciliation on the visceral mass and only slightly on the foot. The surface of the mantle, however, is strongly ciliated, and waste material is removed both by this ciliary action and by sudden violent contractions of the adductors and the whole of the free part of the mantle lobes. This muscular activity is absent in Mysella, in which the mantle cavity is cleansed entirely by ciliary action. The visceral mass, foot and mantle are all strongly ciliated and the mechanism is efficient. In Devonia the cilia on the mantle appear to be the chief means of cleansing the mantle cavity, but Galeomma relies chiefly on muscular activity, assisted by ciliary action on the foot and visceral mass. As is stated above, this variation in the cleansing mechanism of the mantle cavity is also correlated with the differences in environment. Some species, notably Mysella bidentata which lives in conditions where there is a considerable amount of sediment in the water, have particularly strong ciliary action on the surface of the visceral mass, and these cilia, assisted by the comparatively large palps, can sort out large quantities of material quickly and efficiently. In Montacuta substriata which occurs in com- 
paratively clear water, the ciliary action is weaker and the removal of waste material is assisted by muscular contractions which occur at irregular intervals depending on the amount of sediment present. These contractions probably occur infrequently in life except when there is an abnormal amount of sediment in the water.

In some members of this order the larvae are incubated in the mantle cavity to a relatively advanced state of development. Of the species examined Lasaea was found to have larvae with complete bivalve shells, resembling the adult but about one-tenth the size, in the mantle cavity. The larvae of Kellia are liberated at an earlier stage (Lebour, I938), and although they possess bivalve shells they are not so similar to the adult form as those of Lasaea. The larvae of Galeomma are much less advanced than those of Kellia and have no shells when liberated. The period of incubation must therefore be comparatively short. Montacuta ferruginosa was found with shelled larvae in the mantle cavity and their development was observed up to a relatively late stage. The larvae were, however, removed from the mantle cavity for observation and the stage at which they are normally liberated was therefore not observed. No larvae were found in the mantle cavities in M. substriata, Mysella or Devonia, although they are reported to be hermaphrodite with incubation of the larvae in the mantle cavity (Pelseneer, I9II).

A detailed account of the structure and function of the ctenidia has been given by Ridewood (1903) and Atkins (1937), and it has been pointed out by Pelseneer (I9II) that, although all the species examined are included in the order Leptonacea (the Lucinacea according to his classification), Kellia and Galeomma have ctenidia composed of two complete demibranchs while Montacuta, Mysella and Devonia have only one demibranch to each ctenidium. Pelseneer therefore divides the order into two groups, the Leptonidae, Galeommatidae and Erycinidae with two demibranchs and the Montacutidae with a single demibranch. This arrangement is shown in the following table.

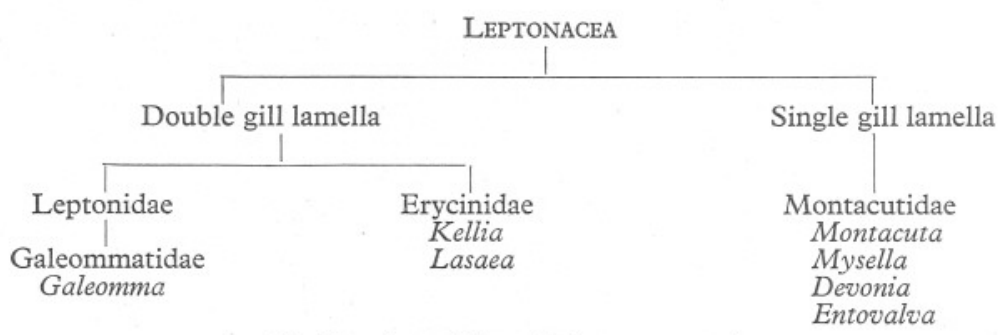

(Table adapted from Pelseneer, I9II)

In every case the single demibranch is the inner, the outer having completely disappeared (Atkins, 1937; Purchon, 1939).

Lasaea is an interesting intermediate stage. The inner demibranch is normal and complete, but the outer demibranch is represented by a short descending lamella only. This is about one-third the length of the inner demibranch. 
Taking Kellia as an example of the primitive condition, this order shows progressive loss of the outer demibranch, Lasaea being the "half-way stage". The loss of one demibranch is the specialized condition found only in the Lucinidae, Montacutidae and Teredinidae (Atkins, I937). In the Lucinidae, a related order included in the sub-class Teleodesmacea (Dall, 1895) and the Teredinidae, however, it is the outer demibranch which remains (Purchon, I939).

The systematic position of the species included in the Leptonacea and the reasons for their inclusion have already been reviewed (Leyborne Popham, I939).

The members of the Leptonacea investigated form part of a series showing the development of commensalism in this order, which has already been described. The descriptions of the habits and of the general anatomy of the mantle cavity included in this paper reveal the modifications which have occurred in relation to the specialized mode of life of those which are commensals.

\section{SUMMARY}

The habitat, external appearance and habits of members of the Erycinidae, Montacutidae and Galeommatidae, three families included in the order Leptonacea, have been investigated and are described.

The ciliary currents of the gills, palps, visceral mass, foot and mantle are described in detail.

There is some reduction in the shell in this order. In Kellia, Lasaea, Montacuta and Mysella the shell is external and the adductor muscles are well developed. In Galeomma the shell and adductors are reduced, and in Devonia the shell is also partially covered by the mantle.

The foot is modified, and all members of this order progress on the flattened ventral surface of the foot which forms a creeping sole. The burrowing habit is lost.

In all species the inhalent current enters the mantle cavity at the anterior end and the exhalent current leaves it posteriorly. There is therefore a direct current through the mantle cavity.

In all except Kellia waste material is removed ventrally through the pedal opening. In Kellia it is shot out through the inhalent opening. Some waste material is also removed anteriorly, but below the inhalent current, in Devonia.

Waste material is removed from the mantle cavity either by ciliary or muscular activity and usually by the combined action of both. In Kellia, Montacuta substriata and Galeomma it is chiefly by muscular action, in Lasaea and Devonia it is chiefly ciliary action, assisted by some muscular contractions, while in Mysella it is entirely due to ciliary action, and in Montacuta ferruginosa muscular and ciliary action appear to play an equal part.

The efficiency of the cleansing mechanism and the speed at which the mantle cavity can be cleared varies with the environment, depending on the amount of sediment normally in the water. 
Mysella, which occurs in a muddy environment, has a strongly ciliated visceral mass and mantle and a current, in addition to the normal rejection currents, which passes material forwards along the dorsal region of the visceral mass to the labial palps. These are comparatively larger than in the other species investigated. This is an additional sorting mechanism, and large quantities of material can be dealt with.

The ctenidia of Kellia and Galeomma are complete, each consisting of two demibranchs, but in Montacuta, Mysella and Devonia the outer demibranch is absent. Lasaea represents an intermediate stage with a complete inner demibranch and a short descending lamella of the outer demibranch only.

The degree of specialization varies with the degree of commensalism. Kellia, which is free-living, is the least specialized member of the group, and Devonia, the most advanced commensal, is the most specialized.

\section{REFERENCES}

Anthony, R., I9ı6. Contribution à l'étude de l'Entovalva (Synapticola) perrieri Malard. Mollusque acephale commensal des Synaptes. Arch. Zool. Expér. Gén., Tome LV, pp. 375-9r.

Atkins, D., I937. On the ciliary mechanisms and interrelationships of lamellibranchs. Parts II and III. Quart. Fourn. Micr. Sci., Vol. LxxIx, pp. 356-7, 4I2-I4.

DALL, W.H., I895. Contributions to the tertiary fauna of Florida. III. A new classification of the Pelecypoda. Trans. Wagner Inst., Vol. III, pp. 485-570.

Fischer, P., I887. Manuel de Conchyliologie et de Paléontologie conchyliologique ou Histoire naturelle des Mollusques vivants. et fossiles, suivi d'un appendice sur les Brachiopodes par D. P. Elert, Paris, I887, Vol. XI, p. I03I.

Forbes, E. \& Hanley, S., I853. British Mollusca, Vol. II. London.

Gardiner, A., 1928. Notes on British Mollusca. Fourn. Conch. London, Vol. xviII, pp. 249-50.

JefFreys, J. G., I863. British Conchology, Vol. II. London.

KeLlOGG, J. L., I9I5. Ciliary mechanisms of lamellibranchs with descriptions of anatomy. Fourn. Morph., Vol. xxvi, pp. 625-70I.

Lebour, M. V., I938. The life history of Kellia suborbicularis. Fourn. Mar. Biol. Ass., Vol. xxII, pp. 447-5I.

Leyborne Popham, M., I939. On Phlyctaenachlamys lysiosquillina gen. and sp.nov., a lamellibranch commensal in the burrows of Lysiosquilla maculata. Sci. Rpt., G. Barrier Reef Exped., I928-9, Brit. Mus. (Nat. Hist.), Vol. vi, pp. 6I-84.

Malard, A. E., I903. Sur un Lamellibranche nouveau, parasite des Synaptes. Bull. Mus. Hist. nat. Paris, Vol. Ix, pp. 342-6.

Marine Biological Association, I93i. Plymouth Marine Fauna. 2nd edition.

Marshall, J. T., I89I. The habitat of Montacuta ferruginosa. Fourn. Conch. London, Vol. vI, pp. 399-404.

Mittre, M. H., I847. Notice sur l'organisation des Galeomma. Ann. Sci. nat. Zool. Paris, 3me série, Vol. vir, pp. 169-8I.

Ohshima, H., I930. Preliminary note on Entovalva semperi sp.nov., a commensal bivalve living attached to the body of a Synaptid. Annot. Zool. Fap., Vol. xIII, pp. 25-6.

I93I. On Entovalva semperi Ohshima, an aberrant commensal bivalve. Venus, Kyoto, Vol. II, pp. I6I-77. 
Pelseneer, P., I89I. Contribution à l'étude des Lamellibranches. Arch. Biol., Vol. xI, pp. I47-3I2.

— I903. Resultats du Voyage du S.Y. Belgica. Zoologie. Mollusques (Amphineures, Gastropodes et Lamellibranches). Anvers.

- I9ri. Les Lamellibranches de l'Expédition du Siboga. Partie Anatomique. Siboga-Expéditie. Mon. LIII $a$.

Purchon, R. D., I939. The reduction of the ctenidia in the Lamellibranchia. Nature, Vol. CXLIV, p. 206.

Ridewood, W. G., I903. On the structure of the gills of the Lamellibranchia. Phil. Trans. Roy. Soc., B, Vol. cxcv, pp. 147-284.

Salisbury, A. E., I932. On Lepton squamosum and Montacuta ferruginosa and some other Molluscs observed at the Salcombe Estuary, Devon. Proc. Malac. Soc., London, Vol. xx, pp. I00-3.

Winckworth, R., I923. Montacuta bidentata (Montagu). Fourn. Conch., Vol. xvir, p. 86.

- 1924. Specimens of molluscs and other animals associated with them found in a day's digging at Salcombe. Proc. Malac. Soc., London, Vol. xvi, p. I.

- 1930. Notes on nomenclature. 5. Some new names for British marine bivalves. Proc. Malac. Soc., London, Vol. xIx, p. I4.

- 1932. The British marine Mollusca. fourn. Conch., Vol. xIx, pp. 2 II-52.

YoNGE, C. M. I936. The evolution of the swimming habit in the Lamellibranchia. Mém. Mus. roy. Hist. Nat. Belg. (2), Vol. III, pp. 77-Io0.

- 1937. The Biology of Aporrhais pes-pelecani (L.) and A. serresiana (Mich.). Fourn. Mar. Biol. Assoc., Vol. xxi, pp. 687-704.

- I939 a. On the mantle cavity and its contained organs in the Loricata (Placophora). Quart. Fourn. Micr. Sci., Vol. Lxxxi, pp. 367-90.

- $1939 b$. The protobranchiate Mollusca; a functional interpretation of their structure and evolution. Phil. Trans. Roy. Soc., B, Vol. ccxxx, pp. 79-I47. 